\title{
Modeling the measured effect of a nitroplasticizer (BDNPA/F) on cookoff of a plastic bonded explosive (PBX 9501)
}

\author{
Michael L. Hobbs, ${ }^{\text {a) }}$ Michael J. Kaneshige, ${ }^{\text {b) }}$ and William W. Erikson ${ }^{\text {c) }}$
}

Sandia National Laboratories, Albuquerque, NM 87185, USA

\begin{abstract}
We have used a modified version of the Sandia Instrumented Thermal Ignition (SITI) experiment to develop a pressure-dependent, five-step ignition model for a plastic bonded explosive (PBX 9501) consisting of 95 wt. \% octahydro-1,3,5,7-tetranitro-1,3,5,7-tetrazoncine (HMX), 2.5 wt. \% Estane ${ }^{\circledR} 5703$ (a polyurethane thermoplastic), and $2.5 \mathrm{wt}$ \% of a nitroplasticizer (NP): BDNPA/F, a 50/50 wt. \% eutectic mixture bis(2,2-dinitropropyl)-acetal (BDNPA) and bis(2,2-dinitropropyl)-formal (BDNPF). The five steps include desorption of water, decomposition of the NP to form $\mathrm{NO}_{2}$, reaction of the $\mathrm{NO}_{2}$ with Estane ${ }^{\circledR}$ and $\mathrm{HMX}$, and decomposition of HMX. The model was fit using our experiments and successfully validated with experiments from five other laboratories with scales ranging from about $2 \mathrm{~g}$ to more than $2.5 \mathrm{~kg}$ of PBX. Our experimental variables included density, confinement, free gas volume, and temperature. We measured internal temperatures, confinement pressure, and ignition time. In some of our experiments, we used a borescope to visually observe the decomposing PBX. Our observations included the endothermic $\beta$ - $\delta$ phase change of the HMX, a small exothermic temperature excursion in low-density unconfined experiments, and runaway ignition. We hypothesize that the temperature excursion in these low density experiments was associated with the NP decomposing exothermically within the PBX sample. This reactant-limited temperature excursion was not observed with our thermocouples in the high-density experiments. For these experiments, we believe the binder diffused to the edges of our high density samples and decomposed next to the highly conductive wall as confirmed by our borescope images.
\end{abstract}

Keywords: Reaction mechanisms; Condensed-phase explosives; Numerical simulation; Scaled experiments

\section{Introduction}

PBX 9501 is composed of 95 wt. \% octahydro-1,3,5,7-tetranitro-1,3,5,7-tetrazoncine (HMX), 2.5 wt. \% Estane $^{\circledR} 5703$ (a polyurethane thermoplastic), and $2.5 \mathrm{wt} . \%$ of a nitroplasticizer (NP or BDNPA/F). The NP is a 50/50 wt. \% eutectic mixture of bis(2,2-dinitropropyl)-acetal (BDNPA) and bis(2,2-dinitropropyl)-formal (BDNPF) with a melting point of $-15^{\circ} \mathrm{C}$, while the BDNPA and BDNPF each have melting points of about $+30{ }^{\circ} \mathrm{C}$ [1]. Prills of PBX 9501 are made of HMX coated with an energetic binder and have a pour density of about $850 \mathrm{~kg} / \mathrm{m}^{3}$ as shown in Fig. 1(a). The higher density samples shown in Fig. 1(b) and 1(c) were made by pressing the prills to 85\% and $95 \%$ of the theoretical maximum density (TMD), respectively. The binder is $5 \mathrm{wt}$. $\%$ of the explosive or about 7.3 vol. \% (3.4\% NP and 3.9\% Estane ${ }^{\circledR}$ ) [2]. The binder provides structural integrity, decreases shock sensitivity, and the nitrated-plasticizers perform better than inert plasticizers. The binder is known to affect the mechanical properties of the explosive, especially at elevated temperatures where the binder softens [3].

\footnotetext{
a) Author to whom correspondence should be addressed. Electronic mail: mlhobbs@sandia.gov. Also at Engineering Sciences Center, Fluid and Reactive Processes Department 1516, Sandia National Laboratories, Albuquerque, NM.

b) Also at Energetic Components, Energetic Material Dynamic and Reactive Science Department 2554, Sandia National Laboratories, Albuquerque, NM.

c) Also at Engineering Sciences Center, Fluid and Reactive Processes Department 1516, Sandia National

Laboratories, Albuquerque, NM.
} 
Recently, we developed and validated a pressure-dependent cookoff model for vented and sealed systems using the plastic bonded explosive PBX 9502 [4], which is composed of $95 \%$ by mass triaminotrinitrobenzene (TATB) and a $5 \%$ by mass chlorotrifluoroethylene/vinylidine fluoride binder. We thought that the same framework could be used for PBX 9501, since the behavior of PBX 9501 in vented and sealed experiments were similar [5]. However, the binder in PBX 9502 is relatively inert compared to the reactive binder in PBX 9501.

Early cookoff models for PBX 9501 did not include the binder in the decomposition mechanism. For example, Jorenby [6] evaluated PBX 9501 cookoff predictions using models of Jaeger [7], McGuire and Tarver [8], and Dickson et al. [9]. These three models were used to simulate Lawrence Livermore National Laboratory (LLNL) scaled thermal explosion experiments (STEX) for confined cylinders [10], LLNL's one-dimensional time-toexplosion (ODTX) experiments [8, 11], Los Alamos National Laboratory (LANL) unconfined spheres [7], and the Naval Air Warfare Center (NAWC) confined cylinder cookoff experiments at China Lake [12]. None of these older models were able to adequately simulate all of these experiments, especially the unconfined spheres. Jorenby [6] attributed the poor prediction of the data to the unconfined state of the explosive.

Henson et al. [13] developed an ignition law for PBX 9501 with the restriction that the model not be applied to unconfined experiments. In contrast, Tarver [14] presented a model for PBX 9501 that was applied to both confined and unconfined ODTX experiments. Tarver's model for PBX 9501 included a four step mechanism for HMX decomposition and single reaction between the HMX decomposition products and binder decomposition products. Tarver determined that reactions between the HMX and binder helped decrease the times to explosion in confined ODTX experiments. In related work, Tarver and Koerner [15] studied three endothermic binders with their HMX and TATB decomposition models to explain the increased ignition times. None of these models were applied to experiments performed at other laboratories.

In the current work, we show that the NP dominates cookoff of PBX 9501 in some of our experiments. For example, in unconfined, low-density experiments, we have observed a temperature excursion prior to a larger exothermic energy release that eventually leads to ignition. When we sealed similar experiments with the same thermal boundary conditions, we observed that the initial temperature rise continued into ignition. Jaeger also observed a temperature excursion followed by a larger exothermic energy release leading to ignition for unconfined 7.62-cm diameter spheres of high density $\left(1840 \mathrm{~kg} / \mathrm{m}^{3}\right)$ PBX 9501 [6]. Jaeger never associated this temperature excursion with the binder [7].

We discovered that the NP in PBX-9501 plays a major role in cookoff of PBX 9501. The remainder of this paper describes the experiments used to determine the role of the NP, development of a model to describe cookoff in PBX 9501 in both vented and sealed configurations at various densities, and validation of the model. We have validated this model using six types of experiments from five different laboratories with scales ranging from a few grams to more than $2.5 \mathrm{~kg}$ of PBX 9501. Our model's ability to scale to larger geometries is attributed to the pressure dependent mechanism, accounting for reactive binder diffusion, and proper accounting of the working pressure of the confining apparatus.

\section{Experiments}

This section describes how we modified the Sandia Instrumented Thermal Ignition (SITI) experiments to visually observe in situ decomposition of PBX 9501 in vented and sealed configurations. We provide the experiment dimensions including confinement details, explosive densities, and boundary conditions. The kinetic parameters and density dependent thermal conductivity for the model described in Section II were determined from these SITI experiments. Various configurations of both vented and sealed SITI experiments with different amounts of free gas volume, which is sometimes referred to as ullage, were also used to validate the model. This section also describes experiments done at other labs that were used to validate our model. These experiments include LLNL's onedimensional-time-to-explosion experiments (ODTX) [8,11], LLNL's scaled thermal explosion experiments (STEX) 
[10], NAWC's confined cylinder experiments [12], LANL's large scale annular cookoff experiment (LSAC) [16], University of Utah's (UofU) Center for the Simulation of Accidental Fires and Explosion (C-SAFE) fast cookoff validation test [17], and LANL's large unconfined sphere experiments [6,7]. Validation consists of simulations of six different types of experiments (SITI, ODTX, STEX, NAWC-pipe, LSAC, C-SAFE-Pipe) from five separate laboratories (SNL, LLNL, NAWC, LANL, and UofU) with PBX 9501 masses ranging from $2 \mathrm{~g}$ (ODTX) to over 2.5 $\mathrm{kg}$ (LSAC).

\subsection{SITI experiments}

We have described the SITI experiments in numerous publications $[4,18,19]$ but give a brief summary in this section since the design was modified to incorporate a borescope camera. Figures 2(a) and 2(e) shows two schematics for the SITI experiment with significantly different gap dimensions. The SITI experiment was filled with prills for the lower density experiments and pressed cylinders for the higher density experiments with examples shown in Fig. 1. Each SITI experiment uses the same thermocouple placement, which is shown in Fig. 2(b). The type $\mathrm{K} 127 \mu \mathrm{m}$ (0.005 in.) diameter thermocouples are located at various radial positions in the center of a $2.54 \mathrm{~cm}$ diameter by $2.54 \mathrm{~cm}$ tall cylinder of PBX 9501. The thermocouples in the pressed explosives are located between two halves of the PBX with each half being a $2.54 \mathrm{~cm}$ diameter by $1.27 \mathrm{~cm}$ tall cylinder.

The small gap SITI in Fig. 2(c) and Fig. 2(d) is shown with two different gap sizes. The geometry in Fig. 2(c) was used for the experiments with prills, which filled this gap. The geometry shown in Fig. 2(d) was used with the higher density pressed pellets with ambient air occupying the gap. The air filled gaps were modeled as radiation enclosures with free convection as discussed in the modeling section III. A schematic of the large gap SITI is shown in Fig. 2(e). Only a few of our large gap SITI experiments included a borescope. The large gap SITI geometry without a borescope is shown in Fig. 2(f).

Table I to III presents 26 SITI experiments showing the effects of the expansion gap volume, density, and confinement. The density was determined based on the mass and volume of PBX 9501 used in each experiment. A control thermocouple on the outside edge of the aluminum confinement ramped from room temperature to a set point temperature $\left(\mathrm{T}_{\mathrm{sp}}\right)$ in $600 \mathrm{~s}$. Uncertainty in the measured initial density, initial temperature, and mass of PBX 9501 is one standard deviation in each of these tables. The free gas volume $\left(\mathrm{V}_{\mathrm{gas}}\right)$ includes gas in the transducer tubing as well as the space above the pressed explosives.

Figure 3 shows ignition plots for the molding powder (46\% TMD), lightly pressed PBX (85\% TMD), and fully pressed PBX (96\% TMD), respectively. Several images from the borescopes are also shown in Fig. 3. The horizontal and vertical axes of the ignition plots represent the inverse of the set point temperature $\left(1000 / \mathrm{T}_{\mathrm{sp}}\right)$ and the ignition time, respectively. In Fig. 3, results from the model described in Section 3 are represented as lines and the experimental data are represented with symbols. The effect of venting is significant for the 46\% TMD and $85 \%$ TMD results. However, the effect of venting is not as pronounced for the fully pressed $97 \%$ TMD results as shown in Fig. 3(d), where the predicted effect of venting was much greater than the measured effect.

Figure 4 shows measured internal temperatures for low density molding powders, lightly pressed samples, and fully pressed SITI samples. The temperature plots show the center thermocouple in red and the other eight thermocouples in green. The $\beta$-to- $\delta$ polymorphic phase change was observed near $445 \mathrm{~K}$. The temperature of the central thermocouple changes from being the coldest to the hottest as the PBX starts to self-heat. One striking feature in Fig. 4 is the temperature excursion shown in the low density and lightly pressed samples. These temperature departures are not noticeable in the highly pressed SITI samples shown in Fig. 4(c). However, a slight temperature rise is noticeable in the vented large ullage run 444vb as shown in Fig. 5(c). A thermal excursion in high density PBX 9501 was also observed by Jaeger [6,7] as reproduced in Fig. 5(d). 
Experiment $413 \mathrm{~s}$ and $414 \mathrm{v}$ were performed with the same boundary temperature as shown in Fig. 4(a). The vented experiment $414 \mathrm{v}$ shows an initial temperature excursion with its maximum occurring at $3270 \mathrm{~s}$. We believe that the excursion is caused by a limiting reactant, such as the NP. As the reactant depletes, the temperature excursion disappears and ignition occurs much later at $11171 \mathrm{~s}$. When the experiment is sealed, such as in experiment 413s, ignition occurs much sooner at $3036 \mathrm{~s}$. The ignition time in the sealed experiment corresponds with the time of the maximum excursion in the vented experiment. This observation was consistent with all of our $46 \%$ TMD and $85 \%$ TMD experiments. For comparison, the center temperature of sealed experiments is plotted using a cyan line on the corresponding temperature plot of the vented experiments.

Figure 5 shows the effects of (a) density on thermal conductivity, (b) free gas volume on ignition time, and (c) venting on ignition time. The thermal conductivity for the fully pressed explosive is greater than the thermal conductivity of the lower density explosives as manifested by the center of the fully pressed explosive heating up faster than the center of the molding powder as shown in Fig. 5(a). Similar data was used to determine the density dependent thermal conductivity used in the model described in Section 3. The method developed by Erikson et al. ${ }^{[20]}$ was not used to reduce this data because of uncertainty near the aluminum-explosive-interface. We used the finite element code in conjunction with the SITI data to determine the density dependent thermal conductivity.

Figure 5(b) implies the reaction rates are pressure dependent. We believe the pressure dependency is caused by a significant gas-phase reaction. The pressure dependency arises since gas concentration is proportional to pressure (P) and inversely proportional to temperature (i.e. concentrations $\propto \mathrm{P} / \mathrm{T}$ ). The ignition delay observed in Fig. 5(b) may have been caused by an exothermic gas phase reaction such an oxidizer (e.g. $\mathrm{NO}_{2}$ ) reacting with a gaseous fuel (e.g. HCN). The ignition time is delayed when the concentration of oxidizers and fuels are reduced by having more free gas volume as shown in Fig. 5(b). The delay in ignition time is even longer when the reactive gases are allowed to leave the system as shown in Fig. 5(c).

We did not observe as large a difference in venting related ignition delay for the fully pressed explosives when compared to the lower density explosives. One explanation for this difference is that the decomposition gases are retained within the PBX for the fully pressed explosive. Since all of the reactive gases do not leave the material, the reaction rates are not reduced even though the sample may be vented. Retention of the gases within the explosive reduces the effect of venting in the highly pressed explosives.

We believe that the NP plays a significant role in cookoff of PBX 9501. This hypothesis is based on migration of the NP as visually observed in our borescope images with examples shown in Fig. 3(e) and Fig. 3(f). The NP is more reactive than HMX as low temperatures [11]. The binder can migrate out of the explosive based on thermal expansion difference between the binder and the HMX and the amount of migration is a function of the density of the PBX. For example, the calculated binder linear expansion coefficient [3] $\left(0.0007 \mathrm{~K}^{-1}\right)$ is about 14 times greater than HMX's measured coefficient of thermal expansion $[21,22]\left(0.00005 \mathrm{~K}^{-1}\right)$. We believe there is sufficient void volume in the lower density samples to accommodate much of the thermal expansion differences. However, insufficient void volume in the higher pressed samples leads to extrusion of the binder as shown in Fig. 3(e) and Fig. 3(f).

\subsection{Experiments from other laboratories}

Table IV describe the geometry, sample mass, and confinement details for six additional PBX 9501 cookoff experiments. For the purposes of the current work, we use the model described in Section III to simulate these experiments for model validation. Table $\mathrm{V}$ gives the boundary conditions for these experiments. Figure 6 gives a simple schematic of each of these experiments. The interested reader should consult the listed references for more detail regarding geometry and boundary conditions for these experiments $[6,10,11,12,16$, and 17]. 
The reference for the models in Table IV did not provide enough detail for all of the required model parameters. For example, we need to know where the decomposition gases can migrate such as free gas volume referred to as ullage in Table IV. We used the experimental drawing, including the O-ring schematic to determine a maximum possible ullage in the ODTX experiments. The working pressure of the confining apparatus is also needed. The ODTX experiment is held together with a hydraulic press that operates at $22000 \mathrm{psi}(152 \mathrm{MPa})$.

The STEX and CSAFE-pipe experiment measured a quasi-static bursting pressure, which was useful. The burst pressure of the NAWC-pipe experiment was estimated using strain gauge data. The maximum working pressure of the LSAC experiment was guessed. We suggest that future cookoff experiments be characterize by including explosive mass, density, free volume, and degree of confinement. We also suggest using thermocouples on the outer confinement for improved understanding of the thermal boundary temperature.

\section{Cookoff model}

This section describes a simple model used to describe cookoff of PBX 9501 in both vented and sealed systems and is based on observations described in the previous section. In the past, we have described cookoff of HMX using a simple two-step model based on an enthalpy formulation [23], a percolation based model [24], and even a complex fourteen step model [25] with limited success. The previously developed models were fit to a limited experimental data set and were not able to predict the response of experiments that were significantly different in size, geometry, and degree of confinement. In the current work, we have been able predict experiments performed in other laboratories by including a simple pressure dependency, accounting for binder migration, and limiting the pressure to the working pressure of the confining apparatus. This section describes this physicsinformed phenomenological model.

\subsection{Reaction mechanism}

Behrens and Maharrey [26] determined the complex decomposition mechanism of HMX shown in Fig. 7 from observations using a simultaneous thermogravimetric modulated beam mass spectrometer (STMBMS). Behrens did not determine rates for all the reaction steps shown in Fig. 7, but did postulate reactions that occur in the gas, solid and molten phases. Controlling mechanisms include unimolecular decomposition and gas phase reactions that occur within a closed pore network. The mechanism for PBX 9501 is more complicated than shown in Fig. 7 since PBX 9501 also contains a reactive binder (2.5\% Estane $^{\circledR}$ and $2.5 \%$ BDNPA/F). HMX can dissolve into the binder as shown by Berghout et al. [27] The complex mechanism can be simplified by noting that each step produces either an oxidizer, a fuel, or both. We exploit this observation to simplify the decomposition mechanism for PBX 9501.

The reaction rates depend on physical and morphological changes that occur within the HMX such as the $\beta$ to $\delta$ phase transition that creates grain structure and promotes cracking and nucleation sites that fill with decomposition gases and a nonvolatile residue (NVR). We have simplified this complex mechanism for PBX 9501 by considering a single reaction that produces $\mathrm{NO}_{2}$, which subsequently reacts with either the binder or the HMX to form equilibrium products. This acceleratory mechanism reacts faster at elevated pressure. We believe $\mathrm{NO}_{2}$ to be a major oxidant as supported by the measurements of Behrens and Maharrey [26].

Figure 8 shows the simplified five-step mechanism that accounts for drying, $\mathrm{NO}_{2}$ evolution, oxidation of Estane ${ }^{\circledR}$ and $\mathrm{HMX}$ with $\mathrm{NO}_{2}$, and unimolecular decomposition of HMX into equilibrium products. Figure 8(a) shows the simplified mechanism. Figure 8(b) shows more detail on the identity of the specific gases for each step in the mechanism and gives the reaction enthalpy for each step. The reaction enthalpy of the $\mathrm{NO}_{2}$ evolution step was chosen to reproduce the temperature excursions observed in the low density SITI tests. This enthalpy is a result of specifying the heat of formation of the nonvolatile residue (NVR) to be $-1400 \times 10^{6} \mathrm{~J} / \mathrm{kgmol}$. The reaction enthalpies were determined at standard temperature and pressure (298 K and $1 \mathrm{~atm})$. 


\subsection{Conservation equations}

Table VI presents the conservation equations and the five-step PBX 9501 reaction mechanism, which were solved using a finite element code, ARIA [28]. A single energy equation is solved with a volumetric energy source for the five reactions. The adsorbed water has a subscript "a" and is a minor species, however, in closed systems with little volume, the pressurization caused by water desorption influences the pressure dependent reactions. The rate and species equations are also given in Table VI. Auxiliary equations needed to calculate the thermodynamic pressure are given in Table VII. Nomenclature for the specific model parameters are given in Table VIII.

All of the rate expressions in Table VI are modified Arrhenius rates. The rates utilize a distributed activation energy model wherein the activation energy is distributed with respect to the progress of the specific reaction. The progress of the reaction is a mole-fraction-based progress variable, as described in Eqn. 13, initially starting at 1 and going to 0 when fully reacted. Figure 9 shows the distribution function multiplier, which is the inverse of the standard normal distribution function. If the value of $\sigma / R$ is positive, like $\sigma_{1} / R$, the effective activation energy starts below the mean, increases with the extent of the reaction, and mimics a diffusion-limited reaction. If the value of $\sigma / R$ is negative; as in the remaining four reaction rates: $\sigma_{2} / R, \sigma_{3} / R, \sigma_{4} / R, \sigma_{5} / R$; the effective activation energy starts above the mean, decreases with the extent of reaction, and accelerates the rates for long induction times common to explosive decomposition. Benefits of using a distributed reaction rate is that the shape of the pressurization curve in time fits this form. For example, the use of more negative values of the distribution parameter causes the pressure time curve to be more concave up. More positive values of the distribution parameter cause the pressure time curve to be more concave down.

\subsection{Thermophysical properties}

We initially tried to fit the thermal conductivity of PBX 9501 using the method described by Erikson et al. [20] during the initial fast ramp (dedicated slow rate ramp experiments were not performed). However, the predicted temperature profiles did not match the measured temperatures sufficiently. We believe the difficulty in applying Erikson's method could be due to transient heat transfer effects from the fast ramp (steady profile had not been established prior to reaching the end of the ramp), contact resistance near the aluminum-explosive interface, and latent enthalpy associated with $\beta$-to- $\delta$ phase change. Consequently, we determined thermal conductivity shown in Fig. 10(a) by matching the finite element predictions of the center temperature to the measured temperature during the initial transient ramp. The thermal conductivities at other densities were determined by linear interpolation. An abrupt change in thermal conductivity occurs at the $\beta$-to- $\delta$ phase change temperature. The phase change is associated with a large change in density and volume as shown in Fig. 11. This increase in volume may be associated with the decrease in thermal conductivity between the $\beta$-HMX and $\delta$-HMX phases.

Figure 10(b) shows the specific heat capacity as well as the specific heat used by Tarver and Tran [11]. The bulk specific heat of PBX 9501, shown in Fig. 10(b), is given in Table VIII with the linear temperature dependence taken from Gibbs and Popolato [29]. The specific heat below $250 \mathrm{~K}$ and above $700 \mathrm{~K}$ were assumed to be constant. An effective capacitance method was used to account for the latent enthalpy due to the $\beta$ to $\delta$ phase transition as well as the melting of HMX at higher temperatures. The values for the effective capacitance and the width of these phase changes are given in Table VIII. A normal distribution centered around the $\beta$ to $\delta$ phase transition temperature $444 \pm 3 \mathrm{~K}$ and $530 \pm 3 \mathrm{~K}$ was used for this thermodynamic phase change. Other researchers have used a more complex kinetic scheme with four reaction steps to capture the $\beta$ to $\delta$ phase transition [30]. We have found that a complex scheme is not needed for cookoff experiments discussed in the current work as long as the latent energy is included, which we do with the effective capacitance method. The reaction energies given in Fig. 8(b) were determined at room temperature using the formation enthalpies listed in Table VIII.

\subsection{Determining kinetic parameters}


The global mechanism in Table IX is an engineering approximation to many complex physical and chemical processes that describe cookoff of PBX 9501. For example Berghout et al. [27] showed that HMX dissolves in the NP at elevated temperatures, but also reported that solubility data for HMX in the NP is not available. Other unsolved problems include identification of major oxidizers and fuels that evolve from the solid to the gas-phase, phase behavior at elevated pressure and temperature, bulk strain induced by gas generation, etc. Our PBX 9501 decomposition model does not address all of these complex processes. Rather, the mechanism is a simple physics-informed phenomenological model with parameters determined to match our small-scale SITI experiments. Our goal is to use this engineering model to predict cookoff behavior (e.g. temperature, pressure, and ignition time) measured at other laboratories with significantly different sizes, shapes, and boundary conditions applied to PBX 9501. Including pressure dependent reactions and accounting for NP migration is the first step toward this goal.

The activation energy and distribution parameters for water desorption (reaction 1) were taken from our previous work on cookoff of PBX 9502 [4]. Adsorbed water is a minor constituent that produces the initial pressure, which is important in sealed systems with little free gas or ullage, such as the ODTX experiment. The second exothermic reaction (reaction 2) was chosen to be pressure independent. We chose the heat of formation of the nonvolatile residue so that reaction 2 would be exothermic. This reaction was then used to match the temperature excursion observed with our low-density, unconfined SITI experiments shown in Fig. 4(a). The third reaction is the reaction of the Estane ${ }^{\circledR}$ with $\mathrm{NO}_{2}$ produced from the NP. Initially, we thought that we could use reaction three to reproduce the cookoff times for the low-density confined SITI experiments by making this reaction pressure dependent. We found that there was not enough energy available from the NP reacting with the Estane ${ }^{\circledR}$ to cause ignition in these experiments. However, the exothermic reaction of the Estane ${ }^{\circledR}$ with $\mathrm{NO}_{2}$ was large enough to bootstrap the fourth reaction to cause early ignition in agreement with the low-density confined SITI experiments. The fifth reaction was added to the mechanism to cause ignition in lower pressure systems.

Confined decomposition with prolonged contact of reactive species justifies the assumption that the decomposition products go all the way to final equilibrium products, which was certainly not observed in Behrens and Maharrey's [26] thermogravimetric experiments performed at low pressure. If this assumption is wrong, then other parts of the model must also be wrong to get a good fit to the data. For example, if half the products were $\mathrm{N}_{2} \mathrm{O}$ and $\mathrm{CH}_{2} \mathrm{O}$, the reaction enthalpy would be different, but the pressurization would also be different. We realize the model presented in the current work does not consider the myriad of reactions observed or calculated with ab initio methods. However, the model is useful to predict pressurization and ignition times for systems of various sizes and shapes. The model also shows how the binder and NP can be a major factor in cookoff of PBX 9501.

\section{Model Predictions}

\subsection{SITI}

Predicted and measured ignition times for the SITI experiments were shown in Fig. 3. In Fig. 3, a correlation for the amount of NP remaining in the explosive was used. This correlation was given in Table VIII in the description of the mass fraction of NP, $\omega_{\mathrm{BDNPA} / \mathrm{F}}$, and the Estane ${ }^{\circledR}, \omega_{\mathrm{Estane}}$. This correlation was determined by setting both $\omega_{\mathrm{BDNPA} / \mathrm{F}}$ and $\omega_{\mathrm{Estane}}$ to 0.025 for the low density molding powders (46\% TMD), and setting these parameters to 0.0083 for the $96 \%$ TMD SITI experiments, and linearly interpolating for other densities. Figure 12 shows the ignition times both with and without this correlation. A better way to determine the amount of binder remaining in the explosive is to solve the Darcy flow equations, which is beyond the scope of the current work.

Figure 12(d) and 12(e) show a comparison between the predicted and measured pressure and internal temperature for SITI experiment \#413s, respectively. Figure 12(f) shows a comparison between the measure and predicted temperature profiles for SITI experiment \#414v. The set point temperature for both of these experiments is 
the same. The only difference is confinement, with experiment \#413s being sealed and \#414v being vented. The temperature excursion annotated in Fig. 12(f) as "Exotherm from NP" is replicated by the model.

Figure 13 shows the average predicted temperature and product yields for experiments $413 \mathrm{~s}$ and $414 \mathrm{v}$. All the parameters in these runs are the same with the exception that the pressure exponents are set to zero for the vented experiment $414 \mathrm{v}$. The rate of the Estane ${ }^{\circledR}$ reaction with $\mathrm{NO}_{2}$ (reaction 2) is much faster in the confined experiment $413 \mathrm{~s}$ and causes thermal runaway. The rate of the Estane ${ }^{\circledR}$ reaction is not as fast in the vented experiment \#414v and this reaction is not responsible for thermal runaway. Rather, the runaway reaction in the sealed experiment is the unimolecular decomposition of the HMX.

Experiment \# 445sb has more free gas volume than the rest of the sealed experiments in Fig. 12(b). The predicted ignition time using the correlation for the binder migration for this experiment is 6,194 seconds in comparison to the measured ignition time of 5,635 seconds. The predicted ignition time without using the correlation is 3974 seconds. The experimental ignition time is between these two predictions. The correlation is only a guide based on observations from the SITI experiments. Safety calculations should be run with the mass fraction of binder ranging from 0 to 0.05 to bound most problems. The following sections give additional guidance for the selection of the mass fraction of binder that participates in the cookoff calculation.

\subsection{ODTX}

A comparison of the model predictions to the ODTX experiment is shown in Fig. 14. The ODTX experiment has little free gas volume. We determined the free gas volume using a computer aided design (CAD) drawing of the copper O-ring. We also accounted for the thermal expansion of the aluminum confinement. We found that the lower temperature ODTX runs were sensitive to the pressure because of the restricted free gas volume. We needed to limit the model pressure to the working pressure of the vessel, which is $152 \mathrm{MPa}(22,000$ psi). We predict that the ODTX vessel vents when the pressure reaches $152 \mathrm{MPa}(22,000 \mathrm{psi})$. After venting, the apparatus may regulate to keep the pressure near the maximum working pressure. We suggest that future ODTX experiments measure pressure to verify this model assumption. Without limiting the pressure, the predicted explosion times were earlier than measured.

We predicted that the ODTX apparatus does not vent gases when the boundary temperature is below the melting point of HMX as annotated on Fig. 14(a). The simulations of ODTX in Fig. 15(a) were performed by assuming none of the binder reacts by setting $\omega_{\text {Estane }}$ and $\omega_{\mathrm{BNDPA} / \mathrm{F}}$ to zero. This assumption is based on migration and reaction of the binder to the edge of the confining vessel where the reaction energy is easily dissipated. The small size and high density of the ODTX experiment favors this assumption. Figure 14(b) shows the calculated explosion times assuming 1) complete binder migration (orange line) and 2) no binder migration (green line). For the latter simulation, the binder dominates the pre-ignition chemistry at low temperatures and causes the explosion times to be faster than the explosion times for the PBX 9501. The yellow symbols in Fig. 14(b) show the experimental explosion times for a pure 50:50 mix of NP and Estane ${ }^{\circledR}$. These results suggest that the binder does not play a significant role in the ODTX experiments with PBX 9501.

Previous models of PBX 9501 have only considered HMX in the formulation and have assumed the binder to be inert. This is also the assumption used for the simulation shown in Fig. 14(a). However, the binder is important for other systems, especially if the geometry is significantly larger than the 2 gram ODTX samples. LLNL's STEX experiment is large enough that significant amounts of binder cannot easily migrate to the boundary and react as shown in the following section.

\subsection{STEX}


We performed three simulations of the STEX experiment allowing various percentages of the binder to react 1) $100 \%$, 2) $28 \%$ based on the SITI correlation for binder migration, and 3) $0 \%$ as done with the ODTX experiment. A comparison of these three model predictions of temperature is shown in Fig. 15. A contour plot is also shown in Fig. 15 showing center ignition for all three simulations. The temperature predictions in Fig. 16 are from the center of the explosive to the edge of the explosive in $10 \%$ spatial increments. The experimentally measured center temperature is also shown in Fig. 15. The geometry and boundary conditions for this experiment were discussed in the "Experiments from other laboratories" Section II.B. The burst pressure, 49.9 MPa (7240 psi), is set based on data for this thin walled STEX experiment. We believe that the size of the explosive is large enough that significant quantities of binder remain within the explosive and plays a major role in the cookoff behavior.

\subsection{NAWC-pipe}

The SITI, ODTX, and STEX experiments were characterized with regard to pressure. The SITI experiments used a pressure transducer for measuring pressure, the ODTX regulated the pressure using a hydraulic press, and the STEX experiments was characterized using a hydraulic pressure burst test. The bursting pressure of the NAWC pipe experiment was estimated using strain gauges. We believe the failure of this experiment to be between 5.5 to 8.3 $\mathrm{MPa}(800$ to $1200 \mathrm{psig}$ ) and set the maximum pressure in the simulations to be $6.9 \mathrm{MPa}$ (1000 psig). The diameter of the NAWC-pipe experiment is about the same as the SITI experiment; however, the length is significantly larger making the mass of explosive in this experiment about twice that of the SITI experiment. We expect the migration of the binder in this experiment to be about the same as in the SITI experiment. Thus, we used the SITI correlation for binder migration to simulate this experiment.

Figure 16 shows a comparison of the predicted temperature from the center of the pipe to the outside of the pipe in $10 \%$ increments. The inset picture is of the NAWC-pipe experiment. The ignition times using the SITI correlation for binder migration matches the measurement. We believe the good agreement is likely due to the diameter of this experiment $(2.54 \mathrm{~cm})$ being the same as the diameter of the SITI experiments $(2.54 \mathrm{~cm})$. Also, setting pipe burst pressure is necessary to match ignition times.

\subsection{CSAFE-pipe}

The maximum working pressure for the CSAFE experiment was set based on a hydro-burst test with the maximum pressure being 5.2 MPa (7541 psi) as shown in Table IV. The measured and predicted pressure were well below the assumed burst pressure. Although the burst pressure was characterized, other parameters were not available for this experiment. For example, free gas volume including gas volume in tubing to instrumentation was not recorded. The temperature and pressure data were noisy and difficult to interpret. We picked an external flux of $640 \mathrm{~W}\left(17.5 \mathrm{~kW} / \mathrm{m}^{2}\right)$ to mimic the measured temperature profiles. Eddings et al. [31] estimated this flux to be 19 $\mathrm{kW} / \mathrm{m}^{2}$ using a one-dimensional analysis. Better boundary conditions measured with thermocouples and better characterization of the free gas volume are suggested for similar experiments.

Figure 17 shows the predicted temperature profile with ignition occurring at the edge of the explosive. Figure 17 also shows the predicted temperatures and pressure within this experiment. Fast cookoff events, like the CSAFE-pipe experiment, do not allow much time for binder migration, and we assume that the binder plays a major role in the ignition. However, firm conclusions are difficult to make when the data is irregular.

\subsection{LSAC}

In contrast to the quickly heated CSAFE-pipe experiment, the LSAC experiment \#3 in Fig. 18 is a slow cookoff experiment confined in brass. Brass cylinders were placed both inside and outside of the PBX annulus and 
sealed using endcaps. Asay et al. [16] did not report the burst pressure of this vessel and we assume it to be $3.4 \mathrm{MPa}$ (500 psig). We do not have a sound reason for choosing $3.4 \mathrm{MPa}(500 \mathrm{psig}$ ) as the working pressure of this vessel. We felt that there could have been gas leaking at the metal-to-metal joints. But these leak paths could have also been sealed by migrating NP/binder. The combination of our chosen burst pressure and assumptions regarding binder migration are likely the cause of our fortuitous match with the LSAC data.

We used the SITI correlation for the binder migration (i.e. we set both $\omega_{\mathrm{BDNPA} / \mathrm{F}}$ and $\omega_{\text {Estane }}$ to 0.007 ). Assuming all the binder migrates to the conductive brass confinement (e.g. setting both $\omega_{\mathrm{BDNPA} / \mathrm{F}}$ and $\omega_{\mathrm{Estane}}$ to zero) will increase the cookoff times. This is because, as the reactive binder decomposes at the conductive surface, its energy release is conducted away by the brass, producing little influence on cookoff. A higher confinement burst pressure will decrease the cookoff time as the higher pressure increases the exothermic reaction rates. We suggest measuring pressure in future experiments.

The LASC experiment had thermocouples on the inside and outside of the PBX giving confidence in the thermal boundary conditions. Internal thermocouples were located at $0.87,1.75$, and $2.62 \mathrm{~cm}$ from the inner wall, which is $1 / 4,1 / 2$, and $3 / 4$ distance through the center of the PBX. Predicted and measured temperatures at these locations is given in Fig. 18. The inset in Fig. 18 shows temperature contours near ignition with the hottest temperature being between the mid-radial or $1 / 2$-radial location and the $3 / 4$-radial locations. Although ignition times are predicted adequately, we were not confident in specifying $3.4 \mathrm{MPa}$ (500 psia) as the burst (or leaking) pressure of the vessel.

\subsection{U-sphere}

The final simulation is of an unconfined sphere [7] referred to as test "2" in reference [6]. Figure 19 shows the predicted temperature profiles using various assumptions regarding the binder migration: 1) the binder does not migrate and all of binder reacts within the PBX (e.g. setting both $\omega_{\mathrm{BDNPA} / \mathrm{F}}$ and $\omega_{\mathrm{Estane}}$ to 0.025$), 2$ ) the binder migrates based on the SITI correlation (e.g. setting both $\omega_{\mathrm{BDNPA} / \mathrm{F}}$ and $\omega_{\mathrm{Estane}}$ to 0.007 ), and 3 ) all of the binder migrates to the edge and does not participate in the cookoff kinetics (e.g. setting both $\omega_{\mathrm{BDNPA} / \mathrm{F}}$ and $\omega_{\mathrm{Estane}}$ to 0.0 ). This experiment is the only experiment that is not only vented, but has no support walls. The spherical PBX was suspended using a wire. The measured temperature of the outer sphere was applied in the model. The model predicts earlier ignition $(56,000 \mathrm{~s}$ to $66,000 \mathrm{~s})$ than was measured $(79,000 \mathrm{~s})$. However, this is a significant improvement over other models that predict ignition times for this unconfined sphere to be between 19,000 s and $50,000 \mathrm{~s}$. We are unsure of heat transfer from the hanging wire, uniformity of the external boundary temperature, swelling of the PBX leading to changes in thermophysical properties, migration of the binder in an unbounded system, etc.

\section{Model uncertainty}

\subsection{Binder migration}

We address the uncertainty in binder migration for the lightly pressed experiment $\# 445 \mathrm{sb}$ ( $\rho_{b o}=1582$ $\mathrm{kg} / \mathrm{m}^{3}$ ) by doing three simulations with all parameters set to the mean values except for the initial mass fraction of the NP $\left(\omega_{\mathrm{BDNPA} / \mathrm{F}}\right)$ and binder $\left(\omega_{\mathrm{Estane}}\right)$. Both these mass fractions are set to 0 (complete migration), 0.012 (set by SITI correlation in Table VIII), and 0.025 (no migration). We do a similar sensitivity study for the fully pressed experiment $\# 441 \mathrm{sb}\left(\rho_{b o}=1778 \mathrm{~kg} / \mathrm{m}^{3}\right)$ by setting the initial NP and binder mass fractions to 0 (complete migration), 0.0083 (set by SITI correlation in Table VIII), and 0.025 (no migration).

Figure 20 shows widely varying responses to changes in the initial NP and binder composition. These results show how sensitive the model predictions are to the presence of the binder and plasticizer. We have found 
that the fully pressed PBX 9501 is the most difficult to characterize with the model. The difficulties include lack of unknown pressure dependency since gases can be held in the closed pore network producing an unknown pressure, binder migration, etc. In Fig. 20(b), the large ullage causes the pressures to be low enough that the binder reaction is slow. The rate of this reaction is too low to cause a runaway reaction. However, the reaction does bootstrap the HMX reaction to initiate runaway about 50 minutes following the temperature excursion. Similar behavior has been measured with PBX 9502 [4].

We suggest that the SITI correlation be used if the experiment is similar to the SITI experiments. For example, the SITI explosive geometry is a cylinder that is $2.54 \mathrm{~cm}$ diameter by $2.54 \mathrm{~cm}$ high. The NAWC-pipe explosive geometry is a cylinder that is $2.17 \mathrm{~cm}$ diameter by $8.89 \mathrm{~cm}$ high. We assume the migration to be similar in this experiment since the diameters are comparable. The predicted ignition times for NAWC-pipe experiments using the SITI correlation were similar to the measured ignition times (14,027 vs. 14,005 s) as discussed previously with Fig. 16. The predicted ignition time (14,027 s) was based on a working pressure of $6.89 \mathrm{MPa}(1000 \mathrm{psi})$ as determined from strain gauge measurements.

The explosive geometry in the ODTX experiments is a $1.27 \mathrm{~cm}$ diameter sphere. Furthermore, the ODTX explosive is fully pressed. The average migration path length in the ODTX experiment is much shorter than in the SITI experiment and the ODTX experiment has no ullage. For the ODTX experiment, we expect all of the binder to migrate to the conductive confinement, whereupon the binder energy is conducted away by the confining aluminum. The predicted and measured ignition times match as shown in Fig. 14.A when the initial NP and binder mass fractions are set to zero to mimic complete migration of the NP and binder. This is essentially the same assumption made when PBX 9501 is modeled as pure HMX.

The binder in the STEX experiment has a significantly larger distance to migrate than either the ODTX or SITI experiments. In STEX, the explosive geometry is a $5.08 \mathrm{~cm}$ diameter by $20.32 \mathrm{~cm}$ long cylinder. The average migration path length in STEX is much larger than either the ODTX or SITI experiments. Thus, we expect less NP and binder migration to the edges of STEX where the energy can be dissipated. Figure 15 shows the measured $(216,900 \mathrm{~s})$ and predicted $(232,415 \mathrm{~s})$ ignition times using a maximum working pressure of $50 \mathrm{MPa}(7250 \mathrm{psi})$. The difference in ignition times could easily be accounted with the uncertainty of the vessel failure pressure.

\subsection{Latin Hypercube Sample (LHS) uncertainty analysis}

Table IX gives parameter uncertainty multipliers for experiment \#413s. All of the uncertainty values were assumed to be uniformly distributed over the given range. The uncertainties in the mass fraction of NP and Estane ${ }^{\circledR}$, $\mathrm{U}_{\omega \mathrm{BDNPA} / \mathrm{F}}$ and $\mathrm{U}_{\omega \mathrm{Estane}}$, were assumed to be small for the low density experiment \#413s since the NP and binder has room for thermal expansion.

A Latin Hypercube Sampling (LHS) technique [32] was used to determine the uncertainty in the predicted temperature, pressure, and ignition time for experiments \#413s. LHS is similar to a Monte Carlo uncertainty analysis with a smart sampling selection scheme. In the current work, 21 LHS samples were run to determine the uncertainty of the PBX 9501 model of experiments \#413s. Figure 21 shows the measured (T: green and P: cyan) and predicted (T: orange and P: pink) center temperatures $\left(\mathrm{T}_{1}\right)$ and pressures predicted with the 21 LHS samples. The mean of the ignition time for experiment \#413s was 3059 seconds and the standard deviation was 55 seconds.

Table IX gives the Pearson correlation coefficient [33], which measures the correlation between the ignition time and the parameters. We believe the binder, in these low density experiments, has sufficient room for thermal expansion and does not extrude to the high conductivity walls. Thus we intentionally specified a small uncertainty in the binder migration parameters for the low density experiments and did not see a significant sensitivity to this value. However, the uncertainty in the specific heat and as well as the rate of the second reaction 
that forms $\mathrm{NO}_{2}$ from the NP were determined to have the highest correlation values of +0.59 and -0.71 , respectively. This correlation is shown in Fig. 21(b).

\section{Summary and conclusions}

We have shown with our SITI experiments that a limiting reactant, such as the NP, produces a temperature excursion before thermal ignition in low density, unconfined PBX 9501. We have also shown that the rates of the reactions responsible for the temperature excursion can be increased by sealing our experiments. In fact, we believe the reactions involved in the excursion can lead to ignition in sealed experiments.

We have added a borescope to our SITI experiment to investigate the role of the binder and NP. We have visually observed migration of the binder or plasticizer to the edge of the explosive in our lightly pressed samples as well as in our highly pressed samples. We qualitatively observed more binder migration in the higher density pressings. We postulate that the thermal expansion of the plasticizer is greater than that of HMX and could be responsible for the binder migration.

We have used our observations to create a simple model useful for interpreting our data. We have also used this model to simulate other PBX 9501 cookoff experiments from five other laboratories with samples ranging from $2 \mathrm{~g}$ to more than $2.5 \mathrm{~kg}$. The amount of confinement ranged from an open sphere hung by a wire, to a small $2 \mathrm{~g}$ sample confined to $152 \mathrm{MPa}(22,000 \mathrm{psi})$. The model has given reasonable agreement for each of these experiments.

We believe that in some cases, the binder migrates to the edge of the explosive, and decomposes next to a large energy sink where the energy release is quickly dissipated. When this happens, the binder and NP do not participate in further exothermic reactions and the cookoff is determined by the HMX kinetics. This could explain why a large number of models can be used to match measured ignition times in small-scale experiments such as the LLNL's ODTX experiment, but are not able to scale-up to larger, unconfined systems.

Our simple phenomenological model has been used with a simple correlation for the binder migration. We believe that better results could be obtained by a more complex model that determines the movement and subsequent reaction of the binder. A constitutive model is needed to determine the stress-strain relationship for a reactive material such as PBX 9501. We also plan to do tests with the explosive LX14 which has 95.5\% HMX and 4.5\% Estane ${ }^{\circledR}$ but not BDNPA/F. The tests with LX14 should help better establish the role of the NP in cookoff of PBX 9501.

\section{Acknowledgments}

Work performed at Sandia National Laboratories. Sandia is a multiprogram laboratory operated by Sandia Corporation, a Lockheed Martin Company, for the United States Department of Energy's National Nuclear Security Administration under Contract DE-AC04-94AL85000. We would like to thank Shane Snedigar for running all of the SITI experiments, Tyler Voskuilen for finite element code development used to implement the pressure dependent model. We would also like to thank Roy Hogan, Leanna Minier, and Tony Geller for their constant interest and enthusiasm regarding our experimental and modeling activities. Our internal reviewers, Cole Yarrington and Marcia Cooper, are also appreciated.

\section{References}

[1] R. B. Rauch, R. Behrens, Vapor Pressures, Mass Spectra and Thermal Decomposition Processes of Bis(2,2Dinitropropyl)acetal (BDNPA) and Bis(2,2-Dinitropropyl)formal (BDNPF), Prop., Explos., Pyrotech. 32 (2007) 97-116.

[2] D. K. Zerkle, B. W. Asay, G. R. Parker, P. M. Dickson, L. B. Smilowitz, B. F. Henson, On the Permeability of Thermally Damaged PBX 9501, Prop., Explos., Pyrotech. 32 (2007) 251-260. 
[3] H. Davande, D. Bedrov, G. D. Smith, Thermodynamic, Transport and Viscoelastic properties of PBX-9501 binder: A molecular dynamics simulations study, Journal of Energetic Materials, 26 (2008) 115-138.

[4] M. L. Hobbs, M. J. Kaneshige, Ignition experiments and models of a plastic bonded explosive (PBX 9502), J. Chem. Phys., 140 (2014) 124203 (1-22).

[5] M. L. Hobbs, M. J. Kaneshige, The Effect of Confinement on Cookoff of a Plastic Bonded Explosive (PBX 9501), Fifteenth International Detonation Symposium, ONR-43-280-15, Office of Naval Research, Arlington, VA (2014) 1478-1487.

[6] J. W. Jorenby, Heat Transfer Analysis and Assessment of Kinetics Systems for PBX 9501, Report No. LA14259-T, Los Alamos National Laboratory, Los Alamos, NM USA, 2006.

[7] D. L. Jeager, Thermal Response of Spherical Explosive Charges Subjected to External Heating, Report No. LA-8332, Los Alamos National Laboratory, Los Alamos, NM USA, 1980.

[8] R. R. Mcguire and C. M. Tarver, Chemical Decomposition Models for the Thermal Explosion of Confined HMX, TATB, RDX and TNT Explosives, Seventh Symposium (International) on Detonation, MP82-334, Office of Naval Research, Arlington, VA (1981) 56-64.

[9] P. M. Dickson, B. W. Asay, B. F. Henson, C. S. Fugard, J. Wong, Measurement of Phase Change and Thermal Decomposition Kinetics Using the Los Alamos Radial Cookoff Test, Report LA-UR-99-3272, Los Alamos Nation Laboratory, Los Alamos, NM USA, 1999.

[10] J. F. Wardell, J. L. Maienschein, The Scaled Thermal Explosion Experiment, Twelfth International Detonation Symposium, ONR 333-05-2, Office of Naval Research, Arlington, VA (2002), 384-393.

[11] C. M. Tarver, T. D. Tran, Thermal decomposition models for HMX-based plastic bonded explosives, Combustion and Flame 137 (2004) 50-62.

[12] A. I. Atwood, P. O. Curran, K. B. Lee, Experimental Progress on a Cookoff Model Validation Effort, Proceeding of the JANNAF 20th Airbreathing Propulsion Subcommittee Meeting, CPIA-PUB-714-VOL-I (2003-0011), (2002) 173-191.

[13] B.F. Henson, L. Smilowitz, B. W. Asay, M. M. Sandstrom, J. J. Romero, An Ignition Law for PBX 9501 from Thermal Explosion to Detonation, Thirteenth International Detonation Symposium, ONR 351-07-01, Office of Naval Research, Arlington, VA (2006) 778-785.

[14] C. M. Tarver, Effects of Exothermic binders on Times to Explosion of HMX-based Plastic Bonded Explosives, Fourteenth International Detonation Symposium, ONR-351-10-185, Office of Naval Research, Arlington, VA (2010) 861-870.

[15] C. M. Tarver, J. G. Koerner, Effects of Endothermic Binders on Times to Explosion of HMX- and TATBBased Plastic Bonded Explosives, Journal of Energetic Materials, 26 (2008) 1-28.

[16] B. Asay, P. Dickson, B. Henson, L. Smilowitz, L. Tellier, N. Glassmaker, M. Greenfield, Large Scale Annular Cookoff Experiment (LASC), Proceeding of the $18^{\text {th }}$ JANNAF Propulsion Systems Hazards Subcommittee Meeting, CPIA-Publ-690-Vol-1 (2000-0547G), (1999) 69-79.

[17] W. Ciro, E. G. Eddings, A. Sarofim, Fast Cookoff Tests Report, Center for the Simulation of Accidental Fires and Explosions, University of Utah, Salt Lake City, UT USA, 2003.

[18] M. J. Kaneshige, A. M. Renlund, R. G. Schmitt, W. W. Erikson, Cook-off Experiments for Model Validation at Sandia National Laboratories, Twelfth International Detonation Symposium, ONR 333-05-2, Office of Naval Research, Arlington, VA (2002) 821-830.

[19] M. L. Hobbs, M. J. Kaneshige, The effect of venting on cookoff of a melt-castable explosive (Comp-B), Sci. Tech. Energetic Materials 76 (2015) 68-74.

[20] W. W. Erikson, M. A. Cooper, M. L. Hobbs, M. J. Kaneshige, M. S. Oliver, S. Snedigar, Determination of thermal diffusivity, conductivity, and energy release from the internal temperature profiles of energetic materials, International Journal of Heat and Mass Transfer 79 (2014) 676-688.

[21] R. K. Weese, A. K. Burnham, J. L. Maienschein, Coefficient of Thermal Expansion of the Beta and Delta Polymorphs of HMX, Report No. UCRL-CONF-205884, Lawrence Livermore National Laboratory, Livermore, CA USA, 2004.

[22] D. G. Thompson, G. W. Brown, R. DeLuca, A. M. Giambra, M. M. Sandstrom, Thermal Expansion of PBX 9501 and PBX 9502 Plastic-Bonded Explosives, Report No. LA-UR-09-05002, Los Alamos National Laboratory, Los Alamos, NM USA, 2009.

[23] M. L. Hobbs, M. J. Kaneshige, Modeling HMX Ignition Using an Enthalpy Formulation, Thirteenth International Detonation Symposium, ONR 351-07-01, Office of Naval Research, Arlington, VA (2006) 507-515. 
[24] M. L. Hobbs, HMX decomposition model to characterize thermal damage, Thermochimica Acta 384 (2002) 291-301.

[25] R. Behrens Jr., S. B. Margolis, M. L. Hobbs, A zero-dimensional model of experimental thermal decomposition of HMX, Eleventh International Detonation Symposium, ONR 33300-5, Office of Naval Research, Arlington, VA (1998) 533-543.

[26] R. Behrens, S. Maharrey, Chemical and Physical Processes that Control the Thermal Decomposition of RDX and HMX, International Journal of Energetic Materials and Chemical Propulsion 5 (2002) 1-6.

[27] H. L. Berghout, S. F. Son, C. B. Skidmore, D. J. Idar, B. W. Asay, Combustion of damaged PBX 9501 explosive, Thermochimica Acta 384 (2002) 261-277.

[28] P. K. Notz, S. R. Subia, M. M. Hopkins, H. K. Moffat, and D. R. Noble, Aria 1.5: User Manual, Report No. SAND2007-2734, Sandia National Laboratories, Albuquerque, NM USA, 2007.

[29] T. R. Gibbs, A. Popolato, editors, LASL Explosive Property Data, University of California Press, Berkeley, CA (1980), 112.

[30] B. F. Henson, L. Smilowitz, B. W. Asay, P. M. Dickson, The $\beta-\delta$ phase transition in the energetic nitramine octahydro-1,3,5,7-tetranitro-1,3,5,7-tetrazocine: Thermodynamics, J. Chem. Phys., 111 (2002) 3780-3788.

[31]E. G. Eddings, W. D. Ciro, C. A. Wight, High Energy Materials in Fires: Influence of the Fire Environment on Violence of Reactions, Presented at the JANNAF 40th Combustion Subcommittee, 28th Airbreathing Propulsion Subcommittee, 22nd Propulsion Systems Hazards Subcommittee, and 4th Modeling and Simulation Subcommittee Joint Meeting, held 13-16 June 2005, Charleston, South Carolina, (2005-0101).

[32] M. D. McKay, R. J. Beckman, and W. J. Conover, A Comparison of Three Methods for Selecting Values of Input Variables in the Analysis of Output from a Computer Code, Technometrics, 21 (1979), 239-245.

[33] L. J. Rodgers, W. A. Nicewander, Thirteen Ways to Look at the Correlation Coefficient, Am. Stat., 42 (1988) 59-66. 


\section{List of Figures}

Fig. 1. Pictures of PBX 9501: (a) $0.85 \mathrm{~g} / \mathrm{cm}^{3}$ (b) $1.58 \mathrm{~g} / \mathrm{cm}^{3}$, and (c) $1.84 \mathrm{~g} / \mathrm{cm}^{3}$. The gas volume fractions for each of these explosives are $54 \%, 14.9 \%$, and $1.3 \%$, respectively.

Fig. 2. Schematic, thermocouple placement, and geometry for various SITI experiments. Schematics with small and large gaps are shown in (a) and (e), respectively. Gaps are filled for low density prills as shown in (c) and empty for pressed PBX 9501 as shown in (d) and (f). The thermocouple placement shown in (b) was the same for all experiments.

Fig. 3. Measured and predicted ignition times for SITI experiments with several images from the borescope.

Fig. 4. Measured internal and control temperatures for SITI experiments with (a) low density molding powders, (b) lightly pressed pellets, and (c) fully pressed pellets. Center temperatures $\left(T_{1}\right)$ are in red with the exceptions of a few cyan for comparing sealed and vented tests. Other radial temperatures, such as $T_{2}$ to $T_{9}$ in Fig. 2(b), are represented by green lines.

Fig. 5. Measured temperatures showing the effect of (a) density on thermal conductivity, (b) free gas volume on ignition delay, and (c) confinement on ignition delay. The temperatures in (d) show a thermal excursion measured by Jaeger $[6,7]$ for a large unconfined high density sphere of PBX 9501.

Fig. 6. Schematics for various experiments described in Table IV: (a) ODTX [11], (b) STEX [10], (c) NAWCpipe [12], (d) CSAFE-pipe [17], (e) LSAC [16], and (f) U-sphere [6,7].

Fig. 7. Reaction mechanism proposed by Behrens and Maharrey [26] for HMX.

Fig. 8. Simplified a) mechanism with b) reaction products and energies.

Fig. 9. Distribution function multiplier, "normsinv" function.

Fig. 10. Thermophysical properties of PBX 9501 used in model: (a) thermal conductivity and (b) bulk specific heat.

Fig. 11. Density and percent volume change as a function of temperature (see Eqn. 21).

Fig. 12. Ignition times for (a) low-density molding powder, (b) lightly pressed pellets, and (c) fully-pressed pellets. Predicted (d) pressure and (e) temperature for sealed experiment $\# 413 \mathrm{~s}$ and (f) temperature for vented experiment $\# 414$.

Fig. 13. Average temperature and product yields predicted for experiments (a) $413 \mathrm{~s}$ and (b) $414 \mathrm{v}$.

Fig. 14. Comparison between predicted (lines) and ODTX data (symbols) [11]: (a) confined PBX 9501 and (b) confined PBX 9501 (blue symbol orange line) and pure binder consisting of 50\% Estane ${ }^{\circledR}$ and 50\% BDNPA/F (yellow symbol and green line). The small black dot in the lines represent the model simulation time with the line linearly interpolated between these predicted ignition times.

Fig. 15. Predicted temperature contours, temperatures, and pressures for the STEX experiment [10].

Fig. 16. Comparison of measured and predicted temperatures in NAWC-pipe experiment [12].

Fig. 17. CSAFE-pipe experiment \#8 [17]: (a) pre-test pictures, (b) predicted temperature profile, and (c) measured and predicted temperatures.

Fig. 18. Predicted and measured temperature profiles in LSAC [16] test \#3. The inset is the predicted temperature contours for this experiment.

Fig. 19. Measured [6] (green line) and predicted (red, cyan, purple) temperatures from the U-sphere experiment.

Fig. 20 Predicted and measured temperatures for experiment (a) \#445sb and (b) \#441sb. 
Fig. 21. (a) Measured and predicted center temperatures and pressures for experiment \#413s. The black line is the mean prediction. The two most correlated parameters that contribute to the predicted uncertainty are plotted in (b). 
TABLE I. SITI runs ${ }^{\mathrm{a}}$ with bulk density ${ }^{\mathrm{b}} 856 \pm 3 \mathrm{~kg} / \mathrm{m}^{3}$ (46\% TMD)

\begin{tabular}{cccccc}
\hline \hline${\text { Run } \#^{\mathrm{c}}}$ & Date & $\mathrm{V}_{\mathrm{gas}}, \mathrm{cm}^{3}$ & $\mathrm{~T}_{\mathrm{sp}}, \mathrm{K}$ & $1000 / \mathrm{T}, \mathrm{K}^{-1}$ & $\mathrm{t}_{\mathrm{ign}}, \mathrm{s}$ \\
\cline { 2 - 6 } $413 \mathrm{~s}$ & $6 / 11 / 15$ & 0.08 & 478.15 & 2.091 & 3036 \\
$415 \mathrm{~s}$ & $6 / 16 / 15$ & 0.08 & 473.15 & 2.113 & 4587 \\
$412 \mathrm{~s}$ & $6 / 9 / 15$ & 0.08 & 468.15 & 2.136 & 6384 \\
$417 \mathrm{~s}$ & $6 / 22 / 15$ & 0.08 & 459.15 & 2.178 & 13134 \\
$419 \mathrm{~s}$ & $7 / 13 / 15$ & 0.08 & 453.15 & 2.207 & 23265 \\
$426 \mathrm{v}$ & $8 / 5 / 15$ & 0 & 483.15 & 2.070 & 7136 \\
$414 \mathrm{v}$ & $6 / 12 / 15$ & 0 & 478.15 & 2.091 & 11171 \\
$416 \mathrm{v}$ & $6 / 17 / 15$ & 0 & 473.15 & 2.113 & 21558 \\
$418 \mathrm{v}$ & $6 / 24 / 15$ & 0 & 469.15 & 2.132 & 28031 \\
\hline \hline
\end{tabular}

${ }^{\mathrm{a}}$ External temperature ramped from $293.5 \pm 0.4 \mathrm{~K}$ to $\mathrm{T}_{\mathrm{sp}}$ in $600 \mathrm{~s}$.

${ }^{\mathrm{b}}$ Bulk density determine from $13.5 \pm 0.01 \mathrm{~g}$ in $15.77 \mathrm{~cm}^{3}$ volume shown in Fig. 1(c).

${ }^{\mathrm{c}} \mathrm{s}$ and $\mathrm{v}$ refer to sealed and vented runs, respectively. 
TABLE II. SITI runs ${ }^{\mathrm{a}}$ with bulk density ${ }^{\mathrm{b}}$ of $1582 \mathrm{~kg} / \mathrm{m}^{3}$ (85\% TMD)

\begin{tabular}{cccccc}
\hline \hline${\text { Run } \#^{\mathrm{c}}}$ & Date & $\mathrm{V}_{\mathrm{gas}}, \mathrm{cm}^{3}$ & $\mathrm{~T}_{\mathrm{sp}}, \mathrm{K}$ & $1000 / \mathrm{T}, \mathrm{K}^{-1}$ & $\mathrm{t}_{\mathrm{ign}}, \mathrm{s}$ \\
\hline $451 \mathrm{~s}$ & $11 / 13 / 15$ & 4.3 & 478.15 & 2.091 & 3072 \\
$445 \mathrm{sb}$ & $10 / 14 / 15$ & 38.3 & 475.15 & 2.105 & 5635 \\
$448 \mathrm{~s}$ & $10 / 26 / 15$ & 4.2 & 473.15 & 2.113 & 3894 \\
$446 \mathrm{~s}$ & $10 / 16 / 15$ & 4.2 & 468.15 & 2.136 & 5550 \\
$452 \mathrm{v}$ & $11 / 17 / 15$ & 4.2 & 478.15 & 2.091 & 9630 \\
$444 \mathrm{vb}$ & $10 / 12 / 15$ & 38.4 & 475.15 & 2.105 & 15088 \\
$450 \mathrm{v}$ & $11 / 9 / 15$ & 4.2 & 473.15 & 2.113 & 17142 \\
$447 \mathrm{v}$ & $10 / 21 / 15$ & 4.2 & 468.15 & 2.136 & 27080 \\
\hline \hline
\end{tabular}

${ }^{\mathrm{a}}$ External temperature ramped from $296.6 \pm 0.4 \mathrm{~K}$ to $\mathrm{T}_{\mathrm{sp}}$ in $600 \mathrm{~s}$.

${ }^{\mathrm{b}}$ Bulk density from $20.36 \pm 0 \mathrm{~g}$ PBX in $12.87 \mathrm{~cm}^{3}$ volume shown in Fig. 1(d).

${ }^{\mathrm{c}} \mathrm{s}, \mathrm{v}$, and $\mathrm{b}$ refer to sealed, vented, and borescope runs, respectively. 
TABLE III. SITI runs ${ }^{\mathrm{a}}$ with bulk density ${ }^{\mathrm{b}}$ of $1779 \mathrm{~kg} / \mathrm{m}^{3}$ (96\% TMD)

\begin{tabular}{cccccc}
\hline \hline Run $\#^{\mathrm{c}}$ & Date & $\mathrm{V}_{\text {gas }}, \mathrm{cm}^{3}$ & $\mathrm{~T}_{\text {sp }}, \mathrm{K}$ & $1000 / \mathrm{T}, \mathrm{K}^{-1}$ & $\mathrm{t}_{\text {ign }}, \mathrm{s}$ \\
\hline $420 \mathrm{~s}$ & $7 / 15 / 15$ & 4.2 & 468.15 & 2.136 & 5685 \\
$428 \mathrm{sb}$ & $8 / 12 / 15$ & 38.6 & 468.15 & 2.136 & 7871 \\
$422 \mathrm{~s}$ & $7 / 22 / 15$ & 4.5 & 463.15 & 2.159 & 7868 \\
$424 \mathrm{~s}$ & $7 / 28 / 15$ & 4.3 & 458.15 & 2.183 & 11736 \\
$441 \mathrm{sb}$ & $9 / 29 / 15$ & 38.5 & 458.15 & 2.183 & 19026 \\
$421 \mathrm{v}$ & $7 / 21 / 15$ & 4.1 & 468.15 & 2.136 & 6739 \\
$423 \mathrm{v}$ & $7 / 24 / 15$ & 4.2 & 463.15 & 2.159 & 12143 \\
$425 \mathrm{v}$ & $8 / 3 / 15$ & 4.2 & 458.15 & 2.183 & 22709 \\
$439 \mathrm{vb}$ & $9 / 23 / 15$ & 38.5 & 458.15 & 2.183 & 29014 \\
\hline \hline
\end{tabular}

${ }^{\mathrm{a}}$ External temperature ramped from $294.2 \pm 0.4 \mathrm{~K}$ to $\mathrm{T}_{\mathrm{sp}}$ in $600 \mathrm{~s}$.

${ }^{b}$ Bulk density from $22.89 \pm 0.00 \mathrm{~g}$ PBX in $12.87 \mathrm{~cm}^{3}$ volume shown in Fig. 1(d).

${ }^{\mathrm{c}} \mathrm{s}, \mathrm{v}$, and b refer to sealed, vented, and borescope runs, respectively. 
TABLE IV. PBX 9501 experiments from various laboratories

\begin{tabular}{|c|c|c|c|c|c|c|c|}
\hline "Acronym & Name & 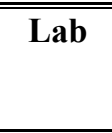 & Date & Geometry & $\begin{array}{c}\text { Mass, } \\
\text { g }\end{array}$ & $\begin{array}{c}\rho_{\mathrm{bo}} \\
\mathrm{g} / \mathrm{cm}^{3}\end{array}$ & $\begin{array}{c}\text { Vessel working } \\
\text { pressure, MPa } \\
\text { (psi) }\end{array}$ \\
\hline " ODTX & $\begin{array}{l}\text { One- } \\
\text { Dimensional- } \\
\text { Time-to- } \\
\text { Explosion }\end{array}$ & " LLNL & 2000 & $\begin{array}{l}1.27 \mathrm{~cm} \text { dia. Sphere } \\
\text { Ullage: } 0.068 \mathrm{~cm}^{3}\end{array}$ & 1.92 & 1.79 & $\begin{array}{c}152 \\
(22000)\end{array}$ \\
\hline STEX & $\begin{array}{l}\text { Scaled thermal } \\
\text { explosion }\end{array}$ & LLNL & 1999 & $\begin{array}{l}\text { cylinder (test } 27) \\
\text { Diameter: } 5.08 \mathrm{~cm} \\
\text { Height: } 20.32 \mathrm{~cm} \\
\text { Ullage: } 30 \mathrm{~cm}^{3}\end{array}$ & 761 & 1.85 & $\begin{array}{c}52(7500) \\
\text { Hydro-burst test }\end{array}$ \\
\hline $\begin{array}{l}\text { NAWC- } \\
\text { pipe }\end{array}$ & $\begin{array}{l}\text { Naval Air } \\
\text { Warfare Center }\end{array}$ & NAWC & 2001 & $\begin{array}{l}\text { cylinder (shot } 011115 \text { ) } \\
\text { Diameter: } 2.17 \mathrm{~cm} \\
\text { Height: } 8.89 \mathrm{~cm} \\
\text { Ullage: } 2.6 \mathrm{~cm}^{3}\end{array}$ & 36 & 1.83 & $\begin{array}{l}7(1000) \text { Strain } \\
\text { gauge estimate }\end{array}$ \\
\hline $\begin{array}{l}\text { CSAFE- } \\
\text { pipe }\end{array}$ & $\begin{array}{l}\text { Center for } \\
\text { simulation of } \\
\text { accidental fires } \\
\text { and explosions }\end{array}$ & U of $U$ & 2002 & $\begin{array}{l}\text { hollow cylinder (Run 8) } \\
\text { Outer dia.: } 10.16 \mathrm{~cm} \\
\text { Inner dia.: } 2.54 \mathrm{~cm} \\
\text { Height: } 10.16 \mathrm{~cm} \\
\text { Ullage: } 51.5 \mathrm{~cm}^{3}\end{array}$ & 1420 & 1.84 & $\begin{array}{c}52(7541) \\
\text { Hydro-burst test }\end{array}$ \\
\hline LASC & $\begin{array}{l}\text { Large scale } \\
\text { annular cookoff }\end{array}$ & LANL & 1999 & $\begin{array}{l}\text { hollow cylinder (Run 3) } \\
\text { Outer dia.: } 15.88 \mathrm{~cm} \\
\text { Inner dia.: } 8.89 \mathrm{~cm} \\
\text { Height: } 10.16 \mathrm{~cm} \\
\text { Ullage: } 207 \mathrm{~cm}^{3} \\
\end{array}$ & 2539 & 1.84 & $\begin{array}{l}\text { Assumed to be } \\
3.4(500)\end{array}$ \\
\hline U-sphere & $\begin{array}{l}\text { Unconfined } \\
\text { sphere }\end{array}$ & LANL & 1980 & $\begin{array}{l}7.62 \mathrm{~cm} \text { dia. Sphere } \\
\text { Ullage: not applicable }\end{array}$ & 426 & 1.84 & 0 \\
\hline
\end{tabular}


TABLE V. Boundary conditions for experiments from various laboratories

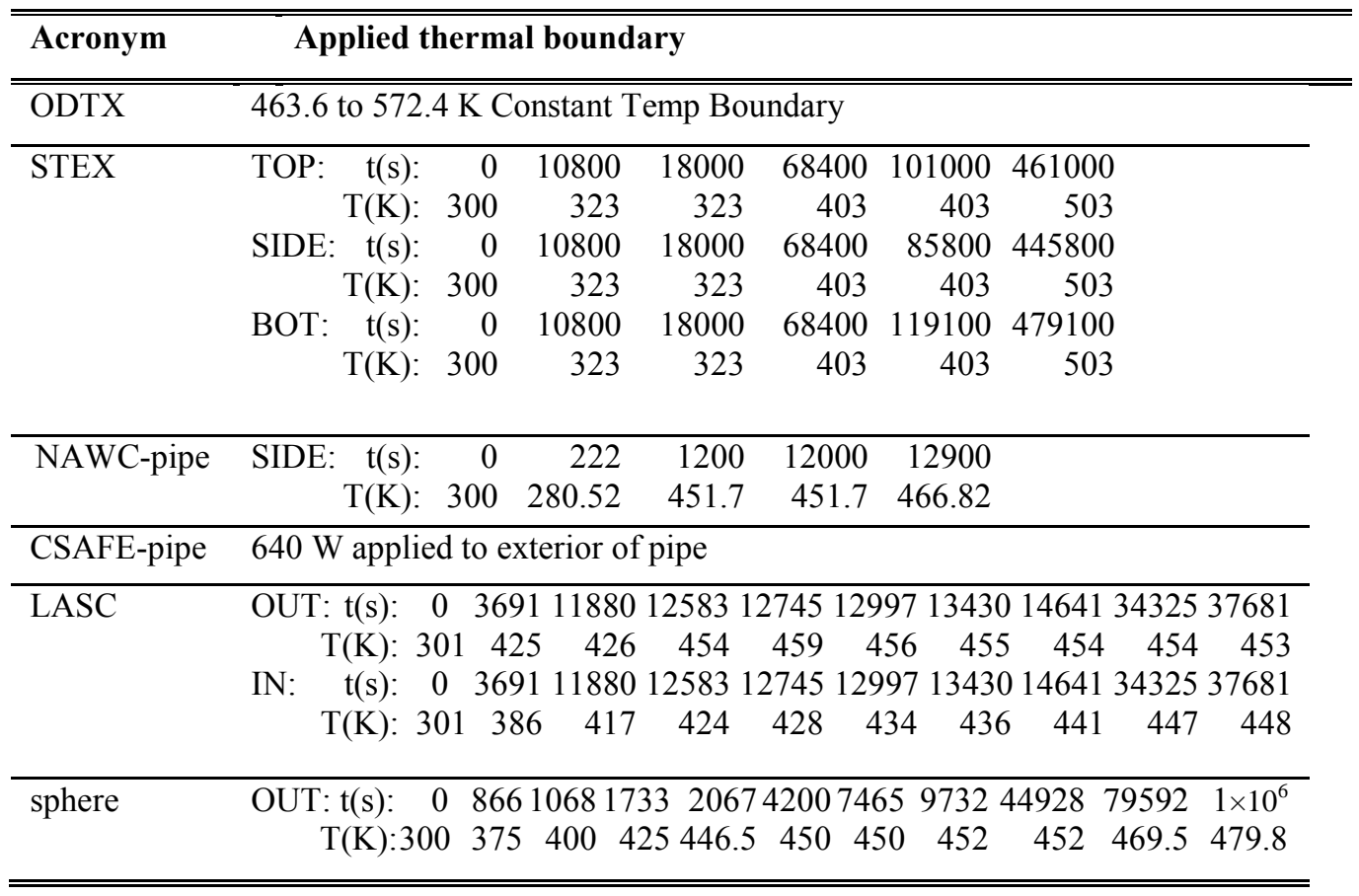


TABLE VI. PBX 9501 ignition model ${ }^{\mathrm{a}}$

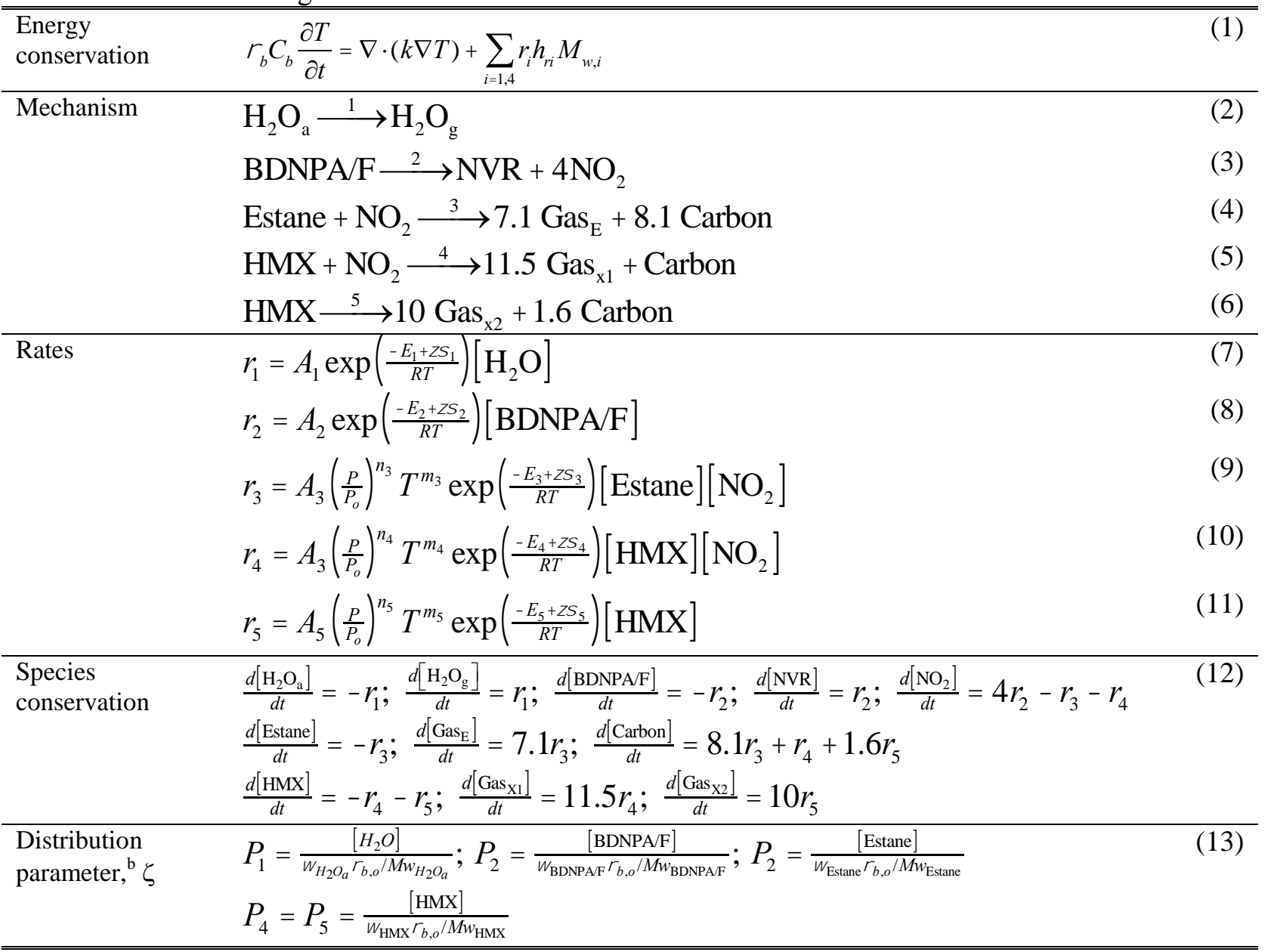

${ }^{a}$ Nomenclature and model parameters are given in Table VIII.

${ }^{\mathrm{b}} \zeta=\operatorname{norminv}\left(P_{i}\right)$, where "norminv" is the inverse of the standard normal cumulative distribution function that has a mean of 0 and a standard deviation of 1 . 
TABLE VII. Auxiliary equations used to calculate the thermodynamic pressure ${ }^{\mathrm{a}}$

\begin{tabular}{|c|c|c|}
\hline Pressure & $P=\frac{z n R T_{\text {ave }}}{V_{g}}$ & (14) \\
\hline Compressibility & $z=1+X \exp (X)$, where $X=\frac{n k \quad x_{i} k_{i}}{v_{g}\left(T_{a v e}+\right)}$ & $(15)$ \\
\hline Gas moles & $n=\left(\left[\mathrm{H}_{2} \mathrm{O}_{\mathrm{g}}\right]+\left[\mathrm{NO}_{2}\right]+\left[\mathrm{Gas}_{\mathrm{E}}\right]+\left[\mathrm{Gas}_{\mathrm{x} 1}\right]+\left[\mathrm{Gas}_{\mathrm{x} 2}\right]\right) d V$ & (16) \\
\hline Ave. gas temperature & $T_{a v e}=\frac{{ }_{V} C T d V}{C d V}$ & (17) \\
\hline Gas volume & $V_{g}=d V$ & (18) \\
\hline Gas volume fraction & $=1 \frac{S_{f} \quad c, o\left(1 \quad{ }_{o}\right)}{c}$ & (19) \\
\hline Reacted solid fraction & $S_{f}=\frac{\left(\left[\mathrm{H}_{2} \mathrm{O}_{\mathrm{a}}\right] M w_{\mathrm{H}_{2} \mathrm{O}_{\mathrm{a}}}+[\mathrm{BDNPA} / \mathrm{F}] M w_{\mathrm{BDNPAF}}+[\mathrm{NVR}] M w_{\mathrm{NVR}}+[\text { Estane }] M w_{\text {Estane }}+[\text { Carbon }] M w_{\text {Carbon }}\right)}{b, o}$ & $(20)$ \\
\hline Condensed density & 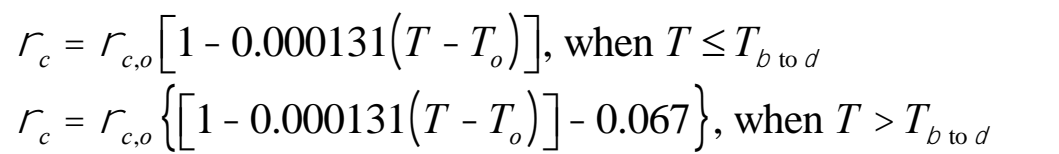 & $(21)$ \\
\hline
\end{tabular}

\footnotetext{
${ }^{a}$ Nomenclature and model parameters are given in Table VIII.
} 
TABLE VIII. Nomenclature and model parameters

\begin{tabular}{|c|c|c|c|}
\hline Symbols & Description & Value & Units \\
\hline $\begin{array}{l}\operatorname{Ln}\left(A_{1}\right), \operatorname{Ln}\left(A_{2}\right), \operatorname{Ln}\left(A_{3}\right), \\
\operatorname{Ln}\left(A_{4}\right), \operatorname{Ln}\left(A_{5}\right)\end{array}$ & $\begin{array}{l}\text { Natural logarithm of the pre- } \\
\text { exponential factors }\end{array}$ & $35,35,35,35$ & $\operatorname{Ln}\left(\mathrm{s}^{-1} \mathrm{~K}^{-\mathrm{n}}\right)$ \\
\hline$\alpha$ & BKW constant & 0.5 & $\mathrm{~K}^{-1}$ \\
\hline$\beta$ & BKW constant & 0.298 & none \\
\hline$\beta_{\mathrm{V}}$ & Thermal expansion coefficient & 0.000131 & $\left(\mathrm{~m}^{3} / \mathrm{m}^{3}\right) \mathrm{K}^{-1}$ \\
\hline$[\mathrm{BDNPA} / \mathrm{F}]$ & NP concentration & Initially $\omega_{\mathrm{BDNPA} / \mathrm{F}} \times \rho_{\mathrm{bo}} / \mathrm{M}_{\mathrm{w}, \mathrm{BDNPA} / \mathrm{F}}$ & $\mathrm{kgmol} / \mathrm{m}^{3}$ \\
\hline $\mathrm{C}$ & Specific Heat & $\begin{array}{l}\text { below } 250 \mathrm{~K}: 919 \\
\text { above } 700 \mathrm{~K}: 2406 \\
250 \text { to } 700 \mathrm{~K}: 92.93+3.305 \times \mathrm{T}, \mathrm{K}\end{array}$ & $\mathrm{Jkg}^{-1} \mathrm{~K}^{-1}$ \\
\hline $\mathrm{C}_{\mathrm{eff},} \beta$ to $\delta$ & $\begin{array}{l}\text { Effective capacitance for } \beta \text { to } \delta \\
\text { phase change using } h_{\text {latent, } \beta-\delta}\end{array}$ & $\begin{array}{l}441 \mathrm{~K}: 1550 \\
444 \mathrm{~K}: 12560 \\
447 \mathrm{~K}: 1570\end{array}$ & $\mathrm{Jkg}^{-1} \mathrm{~K}^{-1}$ \\
\hline $\mathrm{C}_{\text {eff, HMX melt }}$ & $\begin{array}{l}\text { Effective capacitance for HMX } \\
\text { melting phase change using } \\
\mathrm{h}_{\text {latent, melt }}\end{array}$ & $\begin{array}{l}527 \mathrm{~K}: 1835 \\
530 \mathrm{~K}: 80511 \\
533 \mathrm{~K}: 1854\end{array}$ & $\mathrm{Jkg}^{-1} \mathrm{~K}^{-1}$ \\
\hline $\mathrm{C}_{\mathrm{E}}$ & Carbon from Estane ${ }^{\circledR}$ oxidation & Symbol used in mechanism & none \\
\hline $\mathrm{C}_{\mathrm{x} 1}$ & Carbon from HMX oxidation & Symbol used mechanism & none \\
\hline $\mathrm{C}_{\mathrm{x} 2}$ & Carbon from HMX decomposition & Symbol used mechanism & none \\
\hline $\mathrm{C}_{\mathrm{b}}$ & Bulk specific heat & See "C" above & $\mathrm{Jkg}^{-1} \mathrm{~K}^{-1}$ \\
\hline [Carbon] & $\begin{array}{l}\text { Carbon concentration from all } \\
\text { reactions }\end{array}$ & Initially 0 & $\mathrm{kgmol} / \mathrm{m}^{3}$ \\
\hline $\mathrm{E}_{1} / \mathrm{R}, \mathrm{E}_{2} / \mathrm{R}, \mathrm{E}_{3} / \mathrm{R}, \mathrm{E}_{4} / \mathrm{R}, \mathrm{E}_{5} / \mathrm{R}$ & Activation energies divided by $\mathrm{R}$ & $25500,20400,14350,13600,14625$ & $\mathrm{~K}$ \\
\hline [Estane] & Estane concentration & Initially $\omega_{\text {Estane }} \times \rho_{\mathrm{bo}} / M_{\mathrm{w}, \text { Estane }}$ & $\mathrm{kgmol} / \mathrm{m}^{3}$ \\
\hline$\phi$ & Gas volume fraction & Field variable & $\mathrm{m}^{3} / \mathrm{m}^{3}$ \\
\hline$\phi_{\mathrm{o}}$ & Initial gas volume fraction & $1-\rho_{\mathrm{bo}} / \rho_{\mathrm{co}}$ & $\mathrm{m}^{3} / \mathrm{m}^{3}$ \\
\hline$\left[\mathrm{Gas}_{\mathrm{E}}\right]$ & Gas conc. from Estane ${ }^{\circledR}$ oxidation & Initially 0 & $\mathrm{kgmol} / \mathrm{m}^{3}$ \\
\hline$\left[\mathrm{Gas}_{\mathrm{x} 1}\right]$ & Gas conc. from HMX oxidation & Initially 0 & $\mathrm{kgmol} / \mathrm{m}^{3}$ \\
\hline$\left[\mathrm{Gas}_{\mathrm{x} 2}\right]$ & $\begin{array}{l}\text { Gas conc. from HMX } \\
\text { decomposition }\end{array}$ & Initially 0 & $\mathrm{kgmol} / \mathrm{m}^{3}$ \\
\hline$\left[\mathrm{H}_{2} \mathrm{O}_{\mathrm{a}}\right]$ & Adsorbed water concentration & Initially $\omega_{\mathrm{H} 2 \mathrm{Oa}} \times \rho_{\mathrm{bo}} / \mathrm{M}_{\mathrm{w}, \mathrm{H} 2 \mathrm{Oa}}$ & $\mathrm{kgmol} / \mathrm{m}^{3}$ \\
\hline$\left[\mathrm{H}_{2} \mathrm{O}_{\mathrm{g}}\right]$ & Desorbed water concentration & Initially 0 & $\mathrm{kgmol} / \mathrm{m}^{3}$ \\
\hline $\begin{array}{l}\mathrm{h}_{\mathrm{f}, \mathrm{i}} \text { where } \mathrm{i}=\mathrm{H}_{2} \mathrm{O}_{\mathrm{a}}, \mathrm{H}_{2} \mathrm{O}_{\mathrm{g}}, \\
\text { BDNPA/F, NVR, } \mathrm{NO}_{2}, \text { Estane, } \\
\mathrm{G}_{\mathrm{E}} \text {, Carbon, HMX, } \mathrm{G}_{\mathrm{X} 1}, \mathrm{G}_{\mathrm{X} 2}\end{array}$ & Heat of formation of species & $\begin{array}{l}-285.8 \times 10^{6},-241.8 \times 10^{6},-619.2 \times 10^{6}, \\
-1400 \times 10^{6}, 34.2 \times 10^{6},-773 \times 10^{6} \\
-195.7 \times 10^{6}, 0 \times 10^{6}, 75 \times 10^{6} \\
-186.8 \times 10^{6},-175.1 \times 10^{6}\end{array}$ & $\mathrm{Jkgmol}^{-1}$ \\
\hline $\mathrm{h}_{\text {latent }, \beta-\delta}$ & $\begin{array}{l}\text { Latent enthalpy for } \beta-\delta \text { phase } \\
\text { change }\end{array}$ & 33000 & $\mathrm{~J} \mathrm{~kg}^{-1}$ \\
\hline $\mathrm{h}_{\text {latent,m }}$ & Latent enthalpy for HMX melt & 236000 & $\mathrm{~J} \mathrm{~kg}^{-1}$ \\
\hline $\mathrm{i}$ & $\mathrm{i}^{\text {th }}$ reaction & $1,2,3,4,5$ & none \\
\hline$\kappa$ & BKW constant & $10.5 \times 10^{-3}$ & $\begin{array}{c}\AA^{-3} \mathrm{~m}^{3} \mathrm{kgmol}^{-} \\
{ }^{1} \mathrm{~K}^{\alpha} \\
\end{array}$ \\
\hline
\end{tabular}




\begin{tabular}{|c|c|c|c|}
\hline$\sum \mathrm{x}_{\mathrm{i}} \mathrm{k}_{\mathrm{i}}$ & $\begin{array}{l}\text { Average BKW covolume factor. } \\
\text { The covolume is the volume swept } \\
\text { out by the molecule rotating about } \\
\text { its center of mass. The covolume } \\
\text { factor is the covolume multiplied } \\
\text { by } 9.43 \text {. }\end{array}$ & 447 & $\AA^{-3}$ \\
\hline $\mathrm{k}$ & $\begin{array}{l}\beta \text {-HMX thermal conductivity is } \\
\text { only a function of density. } \mathrm{k} \\
\text { changes linearly between } \beta \text { and } \delta \\
\text { phase between } 441 \mathrm{~K} \text { and } 447 \mathrm{~K} \text {. }\end{array}$ & $\begin{array}{l}860 \mathrm{~kg} / \mathrm{m}^{3}: 0.12 \\
1582 \mathrm{~kg} / \mathrm{m}^{3}: 0.25 \\
1778 \mathrm{~kg} / \mathrm{m}^{3}: 0.33 \\
\text { Linear interpolation between } \\
\text { densities }\end{array}$ & $\mathrm{Wm}^{-1} \mathrm{~K}^{-1}$ \\
\hline $\mathrm{k}$ & $\begin{array}{l}\delta \text {-HMX thermal conductivity is } \\
\text { only a function of density. } \mathrm{k} \\
\text { changes linearly between } \beta \text { and } \delta \\
\text { phase between } 441 \mathrm{~K} \text { and } 447 \mathrm{~K} \text {. }\end{array}$ & $\begin{array}{l}860 \mathrm{~kg} / \mathrm{m}^{3}: 0.10 \\
1582 \mathrm{~kg} / \mathrm{m}^{3}: 0.19 \\
1778 \mathrm{~kg} / \mathrm{m}^{3}: 0.21 \\
\text { Linear interpolation between } \\
\text { densities }\end{array}$ & $\mathrm{Wm}^{-1} \mathrm{~K}^{-1}$ \\
\hline $\mathrm{m}_{1}, \mathrm{~m}_{2}, \mathrm{~m}_{3}, \mathrm{~m}_{4}, \mathrm{~m}_{5}$ & Steric factor for reactions 1 to 5 & $0,0,-2,-2,-2$ & $\mathrm{~K}^{-1}$ \\
\hline $\begin{array}{l}\mathrm{M}_{\mathrm{w}, \mathrm{i}} \text {, where } \mathrm{i}=\mathrm{H}_{2} \mathrm{O}_{\mathrm{a}}, \mathrm{H}_{2} \mathrm{O}_{\mathrm{g}} \\
\text { BDNPA/F, NVR, } \mathrm{NO}_{2}, \text { Estane, } \\
\mathrm{G}_{\mathrm{E}} \text {, Carbon, HMX, } \mathrm{G}_{\mathrm{X} 1}, \mathrm{G}_{\mathrm{X} 2}\end{array}$ & Molecular weight of species & $\begin{array}{l}18,18,319,135,46,312,20.4,12 \\
296.2,28.7,27.6\end{array}$ & kg/kgmol \\
\hline $\mathrm{n}$ & Moles of gas & Field variable (Eqn. 16) & kgmol \\
\hline $\mathrm{n}_{1}, \mathrm{n}_{2}, \mathrm{n}_{3}, \mathrm{n}_{4}, \mathrm{n}_{5}$ & Pressure exponent for reactions $1-5$ & $0,0,1,2,0.2$ & none \\
\hline$\left[\mathrm{NO}_{2}\right]$ & Nitric dioxide concentration & Initially 0 & $\mathrm{kgmol} / \mathrm{m}^{3}$ \\
\hline normsinv & $\begin{array}{l}\text { Inverse of the standard normal } \\
\text { distribution }\end{array}$ & function & none \\
\hline$[\mathrm{NVR}]$ & Non-volatile-residue concentration & Initially 0 & $\mathrm{kgmol} / \mathrm{m}^{3}$ \\
\hline $\mathrm{P}$ & Pressure & Initially 0 & $\mathrm{MPa}$ (psig) \\
\hline $\mathrm{P}_{\mathrm{i}}($ where $\mathrm{i}=1,5)$ & Progress of reaction 1 and 5 & Field variable (Eqn. 13) & $\mathrm{kgmol} / \mathrm{kgmol}$ \\
\hline $\mathrm{P}_{\mathrm{o}}$ & Initial pressure & 0.08 (12.1) SITI, 0.1 (14.7) ODTX & $\mathrm{MPa}(\mathrm{psia})$ \\
\hline$\theta$ & BKW constant & 6620 & $\mathrm{~K}$ \\
\hline$\rho$ & Bulk density & Field variable & $\mathrm{kgm}^{-3}$ \\
\hline$\rho_{\mathrm{b}, \mathrm{o}}$ & Initial bulk density & $\begin{array}{l}\text { SITI molding powder: } 856 \\
\text { SITI lightly pressed: } 1582 \\
\text { SITI fully pressed: } 1779 \\
\text { ODTX: } 1787 \\
\text { STEX: } 1847 \\
\text { NAWC-Pipe: } 1825 \\
\text { CSAFE-pipe: } 1840 \\
\text { LASC: } 1840 \\
\text { U-sphere: } 1840 \\
\end{array}$ & $\mathrm{kgm}^{-3}$ \\
\hline$\rho_{\mathrm{c}}$ & Condensed density & Field variable (Eqn. 21) & $\mathrm{kgm}^{-3}$ \\
\hline$\rho_{\mathrm{c}, \mathrm{o}}$ & Initial condensed density (TMD) & 1860 & $\mathrm{kgm}^{-3}$ \\
\hline $\mathrm{R}$ & Gas constant & 0.08206 & $\begin{array}{c}\mathrm{m}^{3} \text { atm kgmol } \\
\mathrm{K}^{-1} \\
\end{array}$ \\
\hline $\mathrm{R}$ & Gas constant & 8314 & $\mathrm{~J} \mathrm{kgmol}^{-1} \mathrm{~K}^{-1}$ \\
\hline$\sigma_{1} / \mathrm{R}, \sigma_{2} / \mathrm{R}, \sigma_{3} / \mathrm{R}, \sigma_{4} / \mathrm{R}, \sigma_{5} / \mathrm{R}$ & $\begin{array}{l}\text { Distribution parameters divided by } \\
\mathrm{R}\end{array}$ & $2500,-200,-500,-2000,-1000$ & $\mathrm{~K}$ \\
\hline $\mathrm{S}_{\mathrm{f}}$ & Reacted solid fraction & Field variable & $\mathrm{kg} / \mathrm{kg}$ \\
\hline $\mathrm{T}$ & Temperature & Field variable & $\mathrm{K}$ \\
\hline $\mathrm{T}_{\text {ave }}$ & Average gas temperature & Global variables & $\mathrm{K}$ \\
\hline
\end{tabular}




\begin{tabular}{|c|c|c|c|}
\hline $\mathrm{T}_{\beta-\delta}$ & $\beta$ to $\delta$ phase change temperature & $\begin{array}{l}444 \text { (normal distribution over } 441 \text { - } \\
447 \text { ) }\end{array}$ & $\mathrm{K}$ \\
\hline $\mathrm{T}_{\text {melt }}$ & HMX melting temperature & $\begin{array}{l}530 \text { (normal distribution over 527- } \\
533 \text { ) }\end{array}$ & $\mathrm{K}$ \\
\hline $\mathrm{T}_{\mathrm{o}}$ & Initial temperature & Average SITI is $294.8 \mathrm{~K}$ & $\mathrm{~K}$ \\
\hline $\mathrm{v}$ & Gas volume & Global variable from Eqn. 18 & $\mathrm{~m}^{3}$ \\
\hline$V_{\text {EM }}$ & Volume of the energetic material & $\begin{array}{l}\text { SITI molding powder: } 15.82 \times 10^{-6} \\
\text { SITI pressed pellets: } 12.87 \times 10^{-6} \\
\text { ODTX: } 1.073 \times 10^{-6} \\
\text { STEX: } 412.0 \times 10^{-6} \\
\text { NAWC-pipe: } 19.71 \times 10^{-6} \\
\text { CSAFE-pipe: } 772.2 \times 10^{-6} \\
\text { LASC: } 1380 \times 10^{-6} \\
\text { U-sphere: } 231.7 \times 10^{-6}\end{array}$ & $\mathrm{~m}^{3}$ \\
\hline$\omega_{\mathrm{BDNPA} / \mathrm{F}}$ & Mass fraction of NP & $\begin{array}{l}\text { No migration: } 0.025 \\
\text { Correlation for migration: } \\
\left(1.63-0.00073 \times \rho_{\mathrm{bo}}\right) \times 0.025\end{array}$ & $\mathrm{~kg} / \mathrm{kg}$ \\
\hline$\omega_{\text {Estane }}$ & Mass fraction of Estane ${ }^{\circledR}$ & $\begin{array}{l}\text { No migration: } 0.025 \\
\text { Correlation for migration: } \\
\left(1.63-0.00073 \times \rho_{\mathrm{bo}}\right) \times 0.025\end{array}$ & $\mathrm{~kg} / \mathrm{kg}$ \\
\hline$\omega_{\mathrm{H} 2 \mathrm{Oa}}$ & Mass fraction of adsorbed water & Initially 0.005 & $\mathrm{~kg} / \mathrm{kg}$ \\
\hline$\omega_{\text {HMX }}$ & Mass fraction of HMX & Initially $0.95-\omega_{\mathrm{H} 2 \mathrm{Oa}}$ & $\mathrm{kg} / \mathrm{kg}$ \\
\hline $\mathrm{X}$ & Part of BKW equation & Defined in Eqn. 15 & none \\
\hline $\begin{array}{l}\mathrm{x}_{\mathrm{i}} \text {, where } \mathrm{i}=\mathrm{N}_{2}, \mathrm{H}_{2} \mathrm{O}, \mathrm{CO}_{2}, \\
\mathrm{CH}_{4}\end{array}$ & $\begin{array}{l}\text { Gas mole fractions for HMX } \\
\text { reaction }\end{array}$ & $0.4,0.36,0.22,0.02$ & mole/mole \\
\hline$\xi$ & normsinv & Field variable & none \\
\hline$\xi_{i}$ & normsinv for $\mathrm{i}^{\text {th }}$ reaction & Field variable & none \\
\hline$\zeta$ & Melt rate acceleration factor & $1+0.5 *(1+\tanh (\mathrm{T}-530)) * 100$ & none \\
\hline $\mathrm{Z}$ & Compressibility & Global variables (Eqn. 15) & none \\
\hline
\end{tabular}


TABLE IX. Parameter uncertainty for experiment \#413s

\begin{tabular}{|c|c|c|c|c|}
\hline Symbols & Description of multiplier $^{a}$ & 4113s & $\overline{\mathbf{r}^{\mathbf{b}}}$ & $\overline{\mathbf{r}^{2}}$ \\
\hline$\overline{\mathrm{U}_{\beta v}}$ & Volumetric expansion & $1 \pm 0.03$ & 0.01 & 0.00 \\
\hline $\mathrm{U}_{\mathrm{Cb}}$ & Bulk specific heat & $1 \pm 0.05$ & 0.59 & 0.35 \\
\hline $\mathrm{U}_{\text {hlatent, } \beta-\delta}$ & Latent enthalpy $(\beta-\delta)$ & $1 \pm 0.05$ & 0.15 & 0.02 \\
\hline $\mathrm{U}_{\text {hlatent, melt }}$ & Latent enthalpy (HMX melt) & $1 \pm 0.05$ & 0.10 & 0.01 \\
\hline $\mathrm{U}_{\mathrm{khi}}$ & High temperature conductivity & $1 \pm 0.05$ & -0.11 & 0.01 \\
\hline $\mathrm{U}_{\mathrm{klo}}$ & Low temperature conductivity & $1 \pm 0.05$ & -0.08 & 0.01 \\
\hline $\mathrm{U}_{\mathrm{r} 1}$ & Reaction (1) & $1 \pm 0.05$ & -0.06 & 0.00 \\
\hline $\mathrm{U}_{\mathrm{r} 2}$ & Reaction (2) & $1 \pm 0.05$ & -0.71 & 0.50 \\
\hline $\mathrm{U}_{\mathrm{r} 3}$ & Reaction (3) & $1 \pm 0.05$ & -0.28 & 0.08 \\
\hline $\mathrm{U}_{\mathrm{r} 4}$ & Reaction (4) & $1 \pm 0.05$ & 0.05 & 0.00 \\
\hline $\mathrm{U}_{\mathrm{r} 5}$ & Reaction (5) & $1 \pm 0.05$ & -0.24 & 0.06 \\
\hline $\mathrm{U}_{\rho \mathrm{\rho bo}}$ & Initial bulk density & $1 \pm 0.02$ & -0.29 & 0.08 \\
\hline $\mathrm{U}_{\mathrm{T} \beta-\delta}$ & $\beta$ to $\delta$ phase change temp. & $1 \pm 0.005$ & -0.01 & 0.00 \\
\hline $\mathrm{U}_{\mathrm{Tmelt}}$ & HMX melt temperature & $1 \pm 0.005$ & 0.09 & 0.01 \\
\hline $\mathrm{U}_{\text {ullage }}$ & Free gas volume & $1 \pm 0.005$ & 0.06 & 0.00 \\
\hline $\mathrm{U}_{\omega \mathrm{BDNPA} / \mathrm{F}}$ & BDNPA/F initial mass fraction & $1 \pm 0.005$ & 0.06 & 0.00 \\
\hline $\mathrm{U}_{\omega \mathrm{Estane}}$ & Estane ${ }^{\circledR}$ initial mass fraction & $1 \pm 0.005$ & 0.26 & 0.07 \\
\hline $\mathrm{U}_{\mathrm{H} 2 \mathrm{Oa}}$ & Mass fraction of adsorbed water & $1 \pm 0.10$ & 0.02 & 0.00 \\
\hline $\mathrm{U}_{\Sigma \mathrm{xiki}}$ & BKWS covolume factor & $1 \pm 0.05$ & -0.15 & 0.02 \\
\hline $\mathrm{U}_{\zeta}$ & Melt rate acceleration factor & $1 \pm 0.05$ & 0.02 & 0.00 \\
\hline
\end{tabular}

${ }^{a}$ Multipliers for the mean values given in Table VIII. The range represents a uniform distribution.

${ }^{\mathrm{b}}$ This is the Pearson's correlation coefficient for the ignition time. 
(a) Prills at $46 \%$ TMD $0.85 \mathrm{~g} / \mathrm{cm}^{3}, \phi=54 \%$

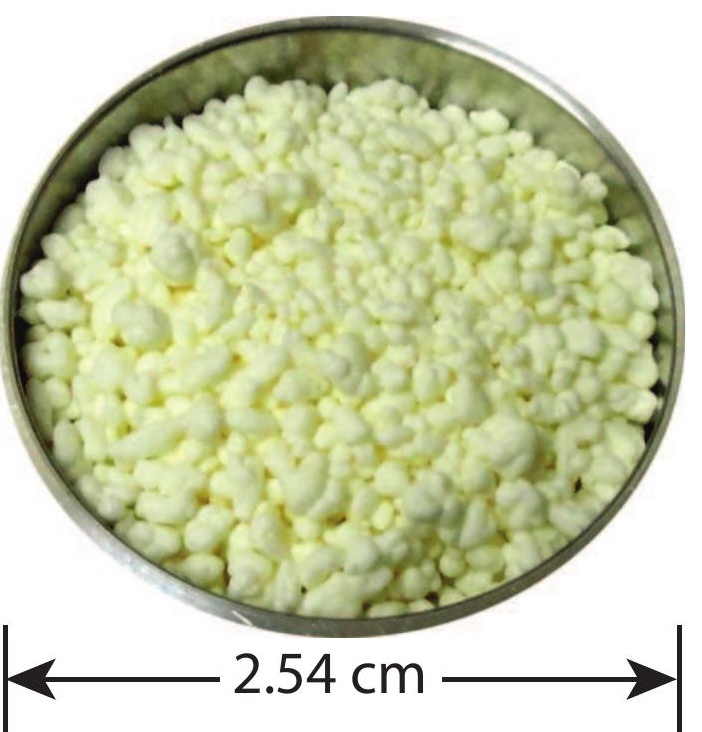

(b) Pressed to $85 \%$ TMD $1.58 \mathrm{~g} / \mathrm{cm}^{3}, \phi=14.9 \%$

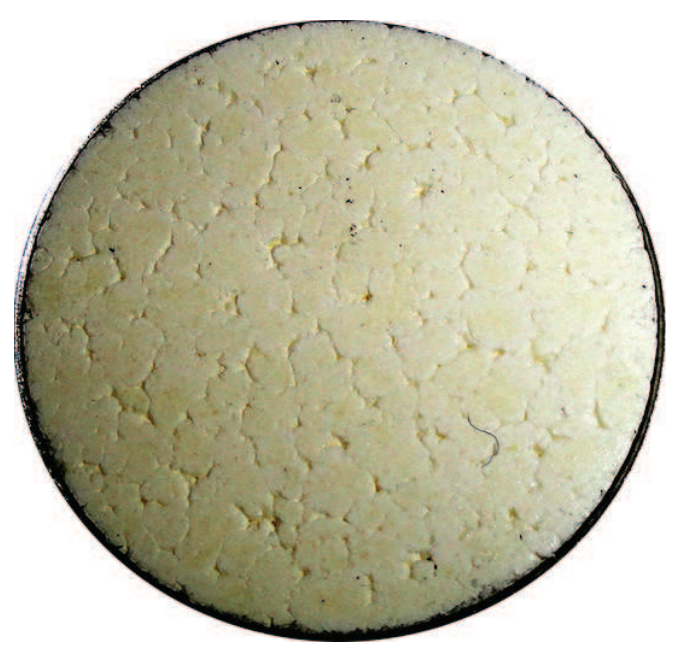

(c) Pressed to $96 \% \mathrm{TMD}$ $1.84 \mathrm{~g} / \mathrm{cm}^{3}, \phi=1.3 \%$

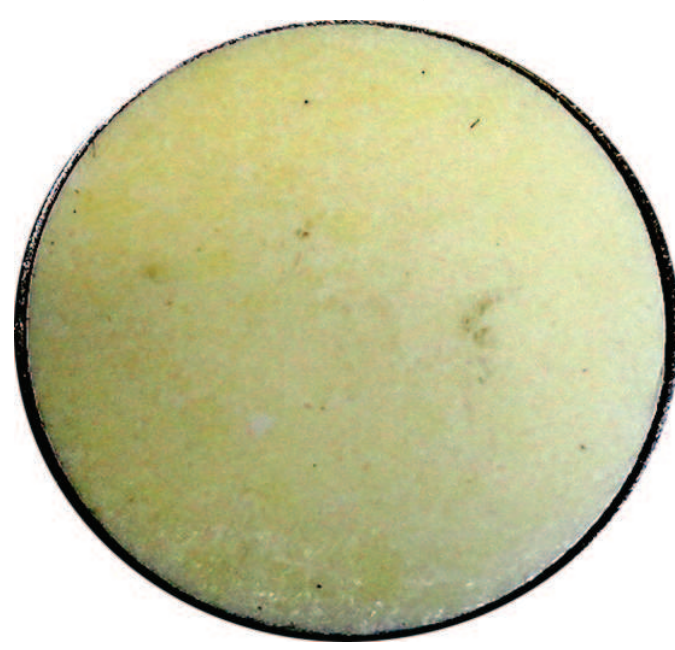


Figaresthematic of small gap SITI

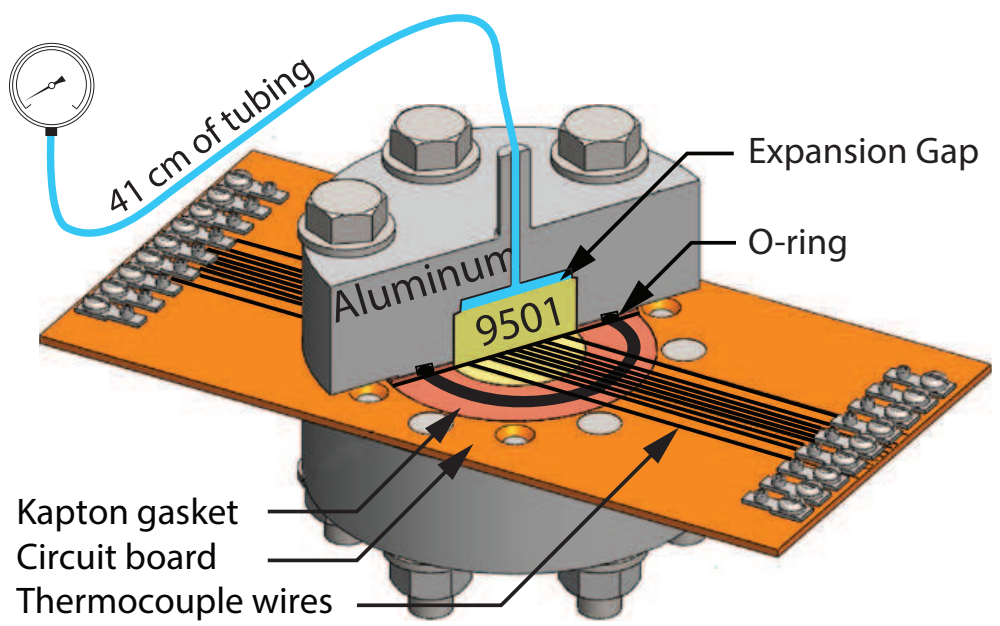

(c) expansion gap filled with prills

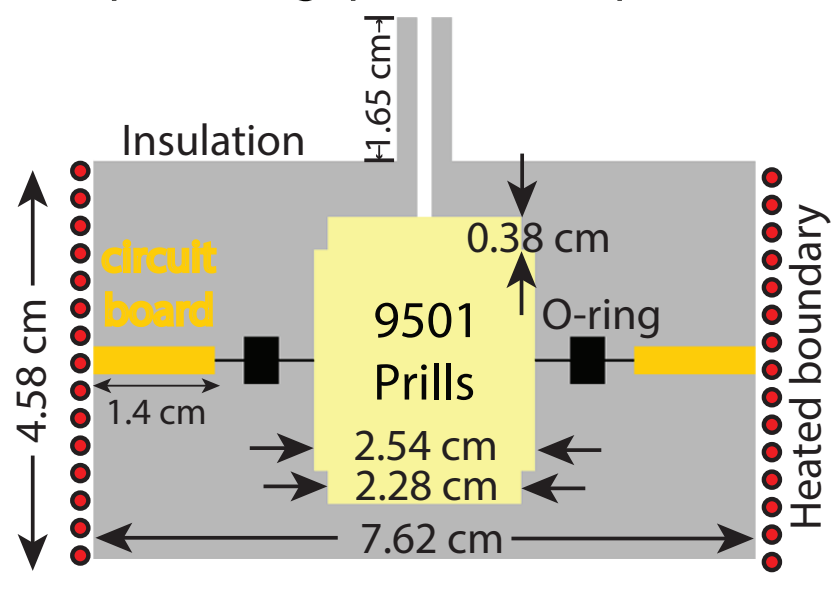

Insulation

(e) schematic of large gap SITI

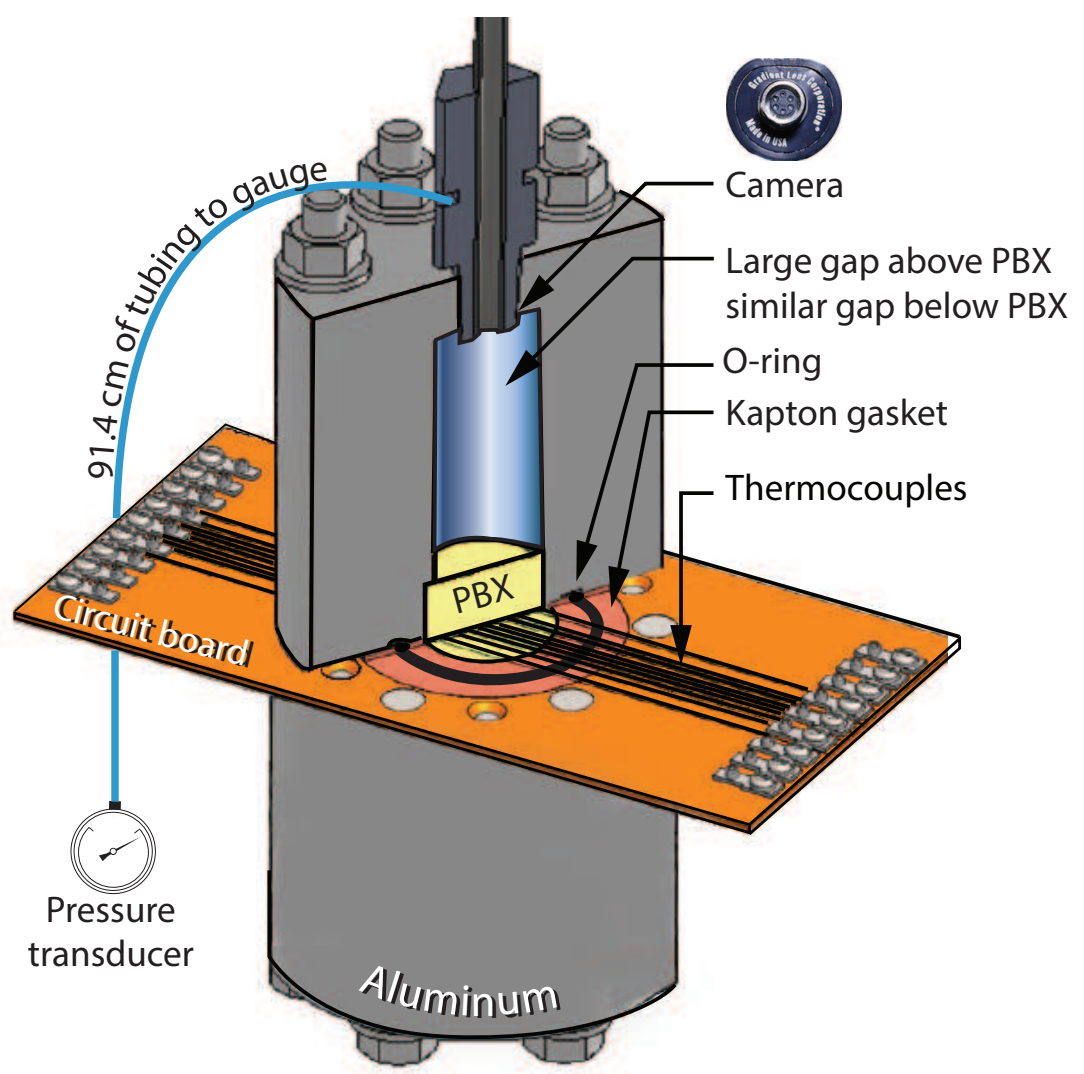

(b) thermocouple placement

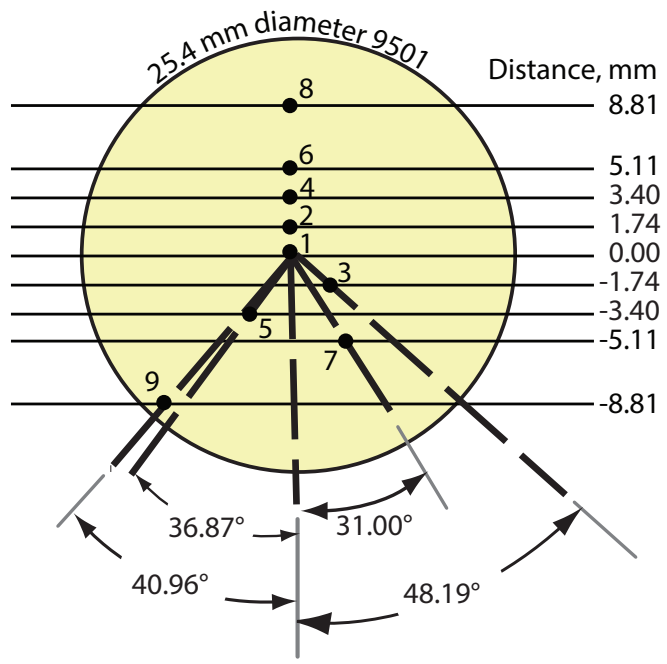

(d) expansion gap treated as radiation enclosure with natural convection

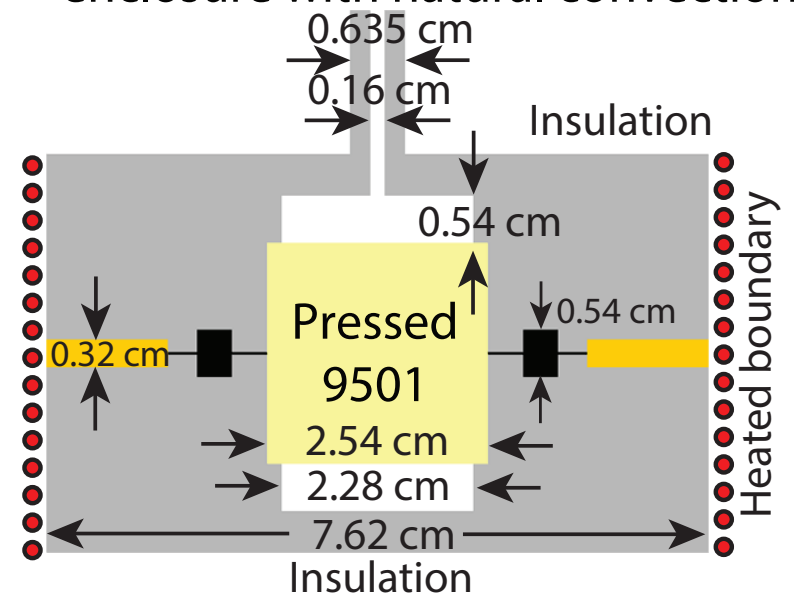

(f) expansion gap treated as radiation enclosure with natural convection

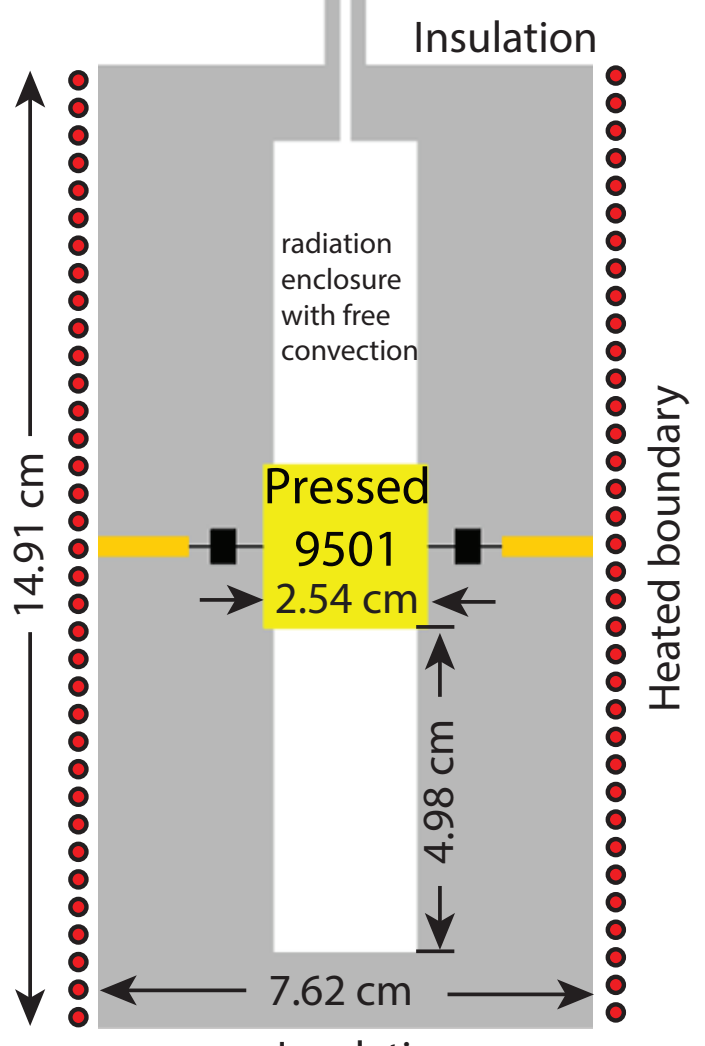


$\begin{array}{lll}(\text { Figghre } 3 & \text { Data (symbols) } & \text { Triangles (vented) } \\ \text { Model (lines) } & \text { Circles (sealed) }\end{array}$

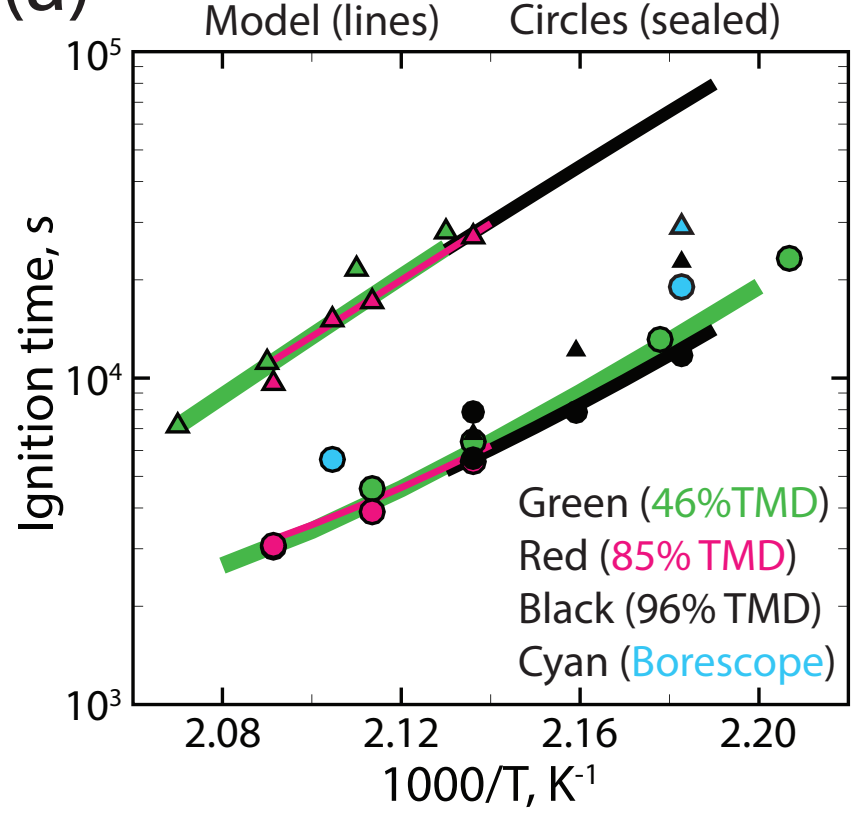

(b) $\rho_{\mathrm{o}}=0.860 \mathrm{~g} / \mathrm{cc}(46 \% \mathrm{TMD})$

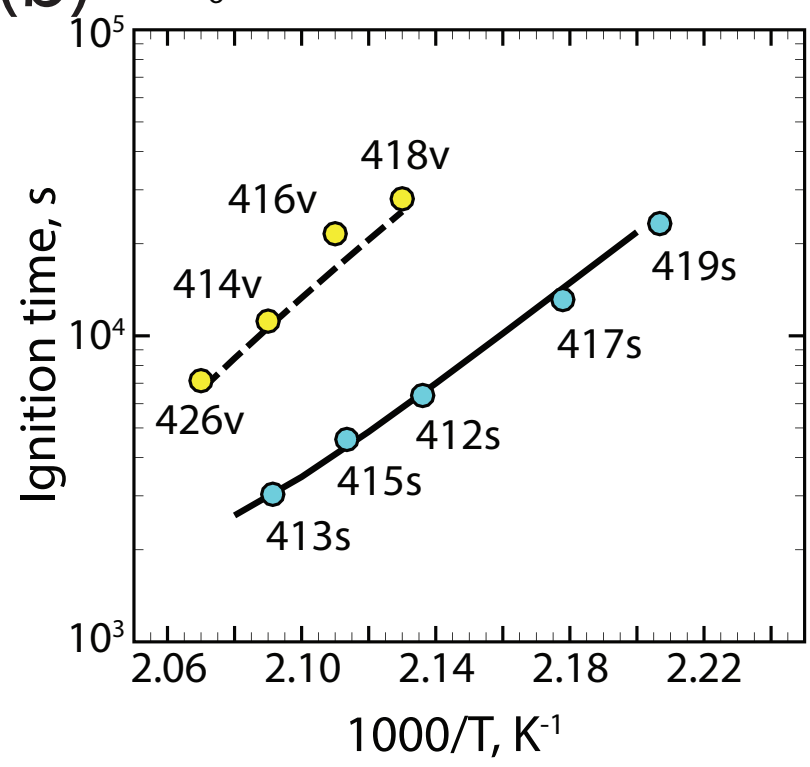

(C) $\rho_{\mathrm{o}}=1.582 \mathrm{~g} / \mathrm{cc}(85 \% \mathrm{TMD})$

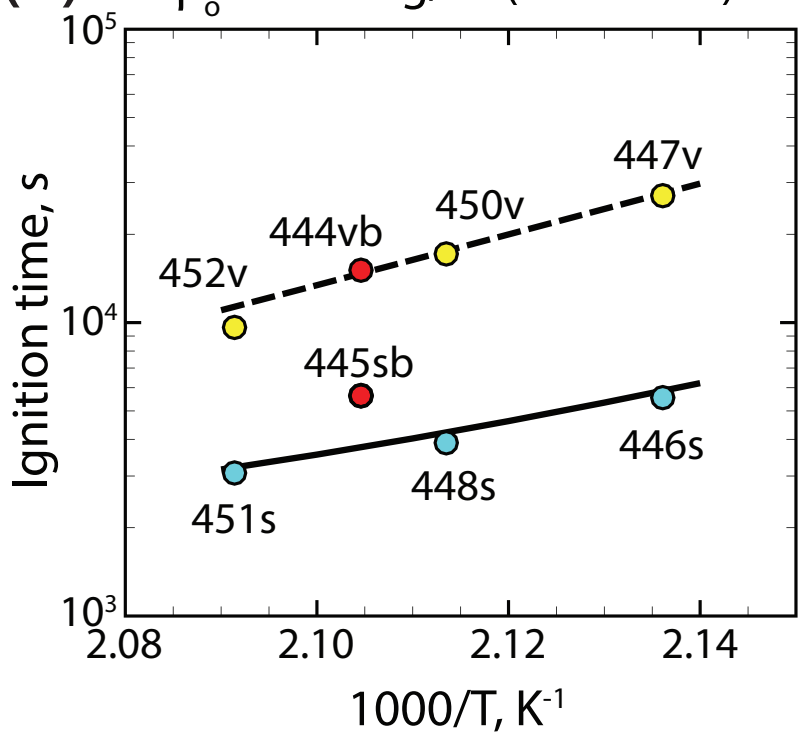

(e) $85 \% \mathrm{TMD}$

\section{5sb}

(d)

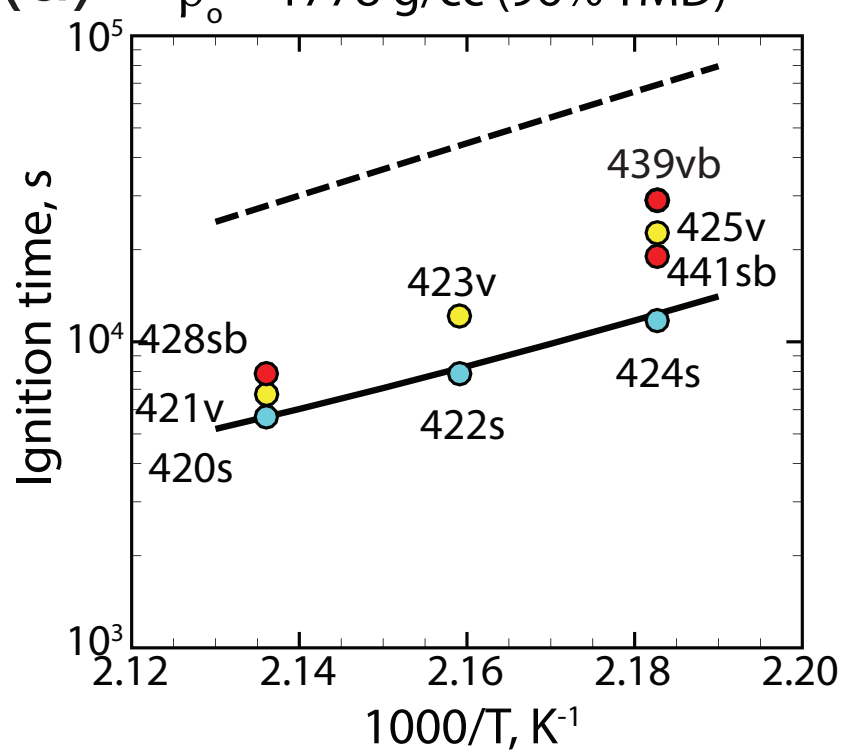

(f) $96 \% \mathrm{TMD}$

\section{$428 \mathrm{sb}$}

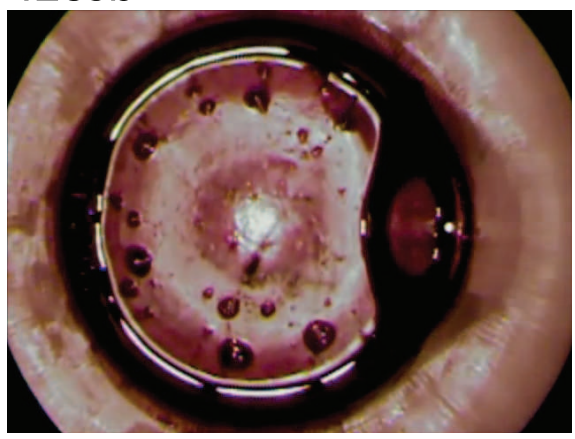

$441 \mathrm{sb}$

$444 \mathrm{vb}$

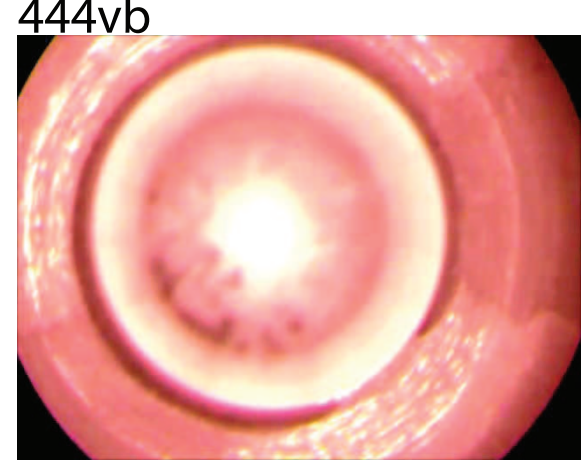

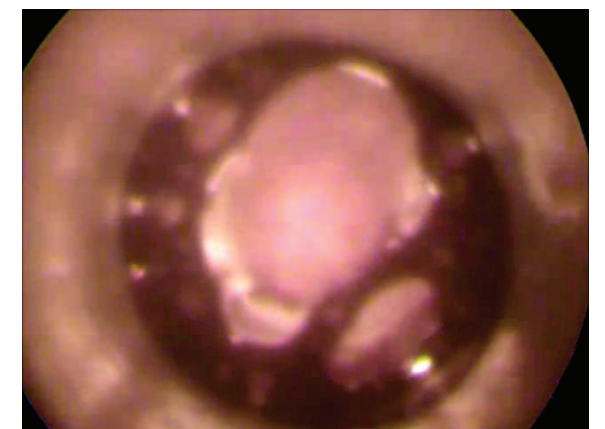


(a)

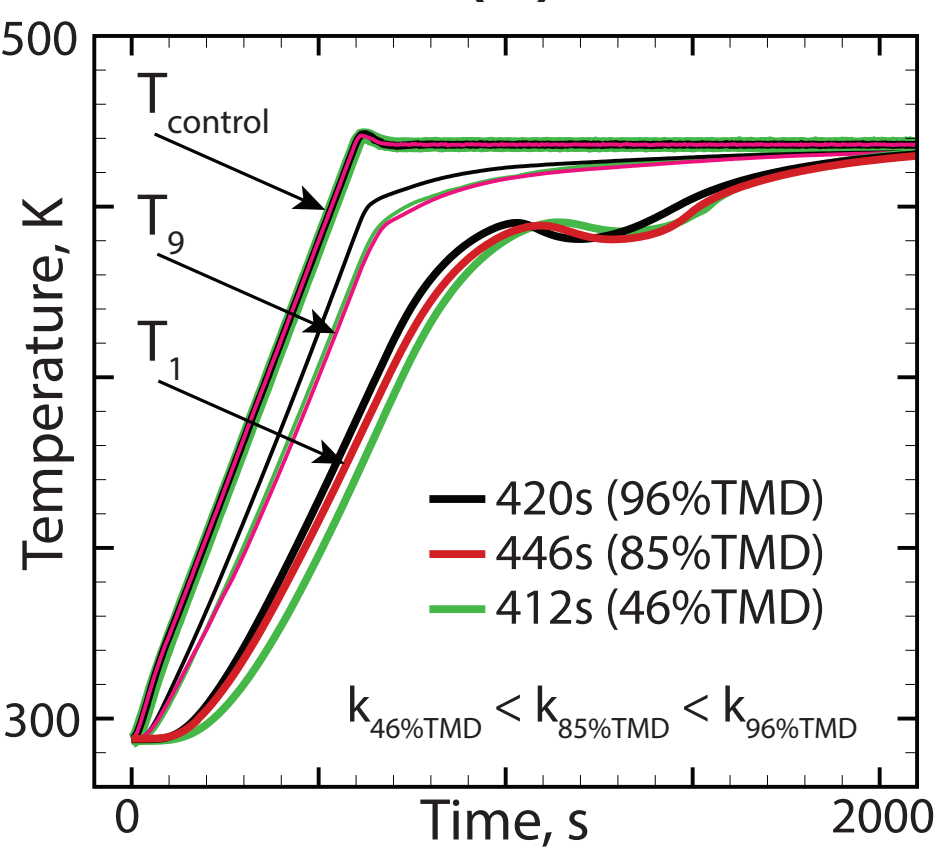

(c)

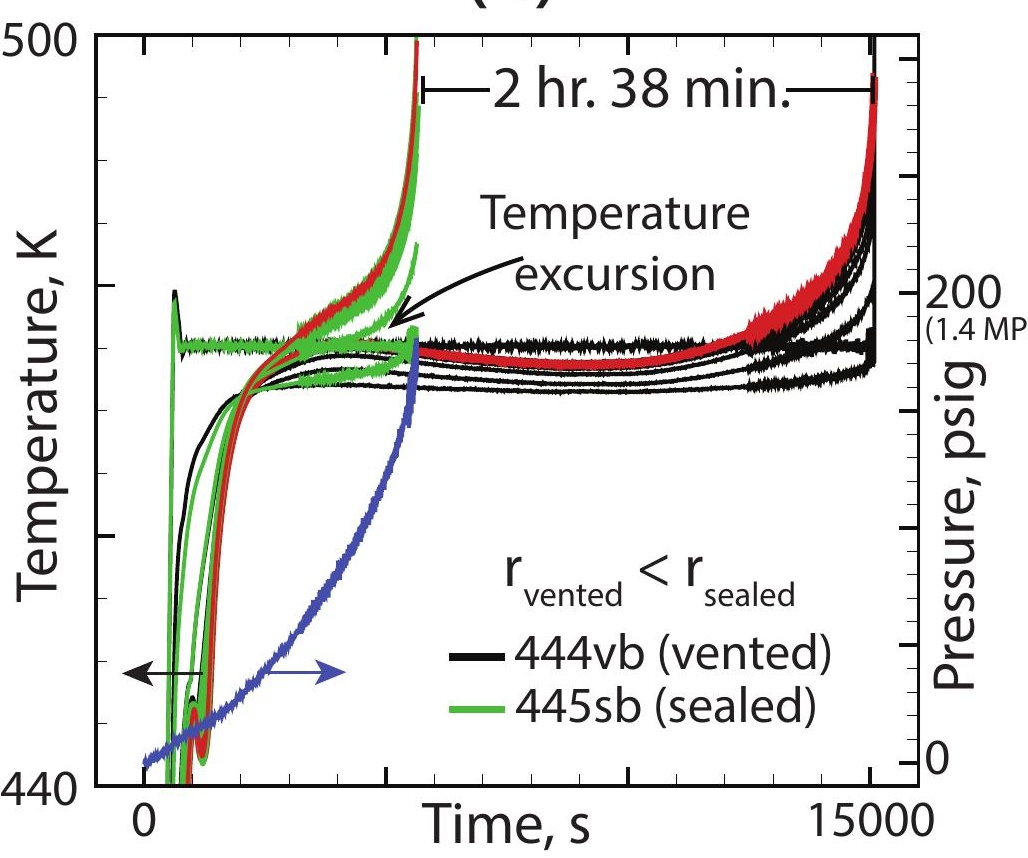

(b)

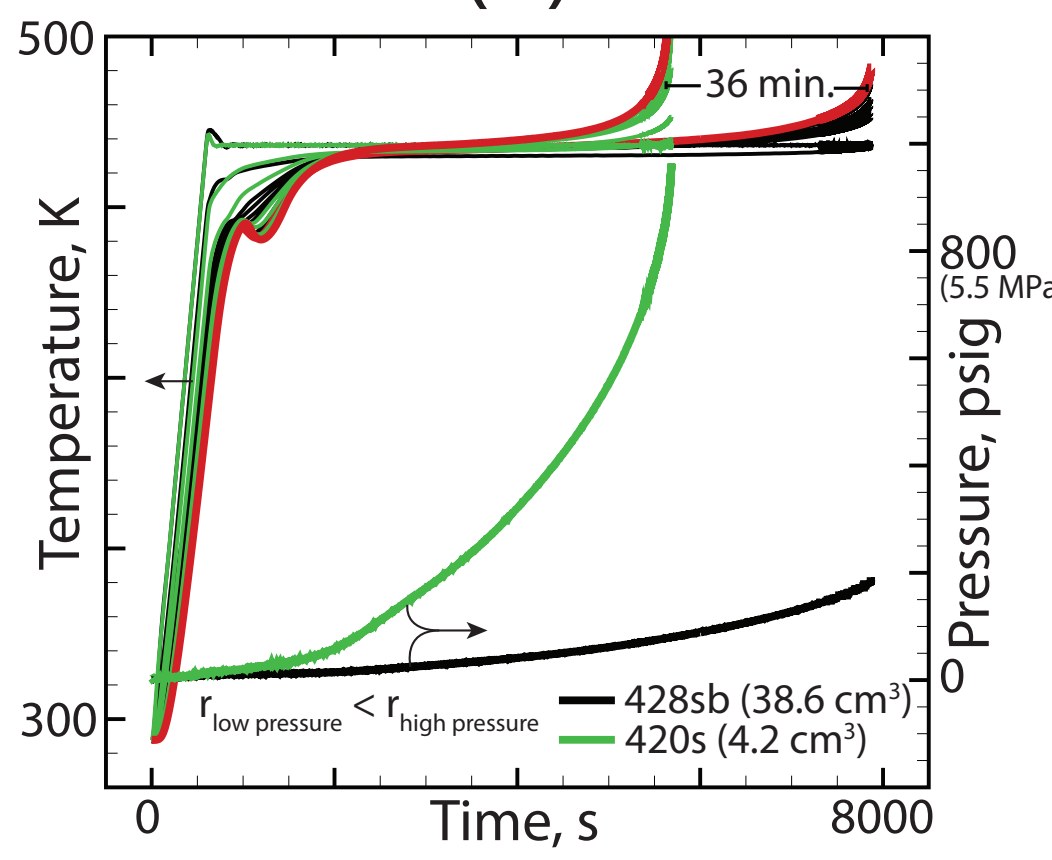

(d)

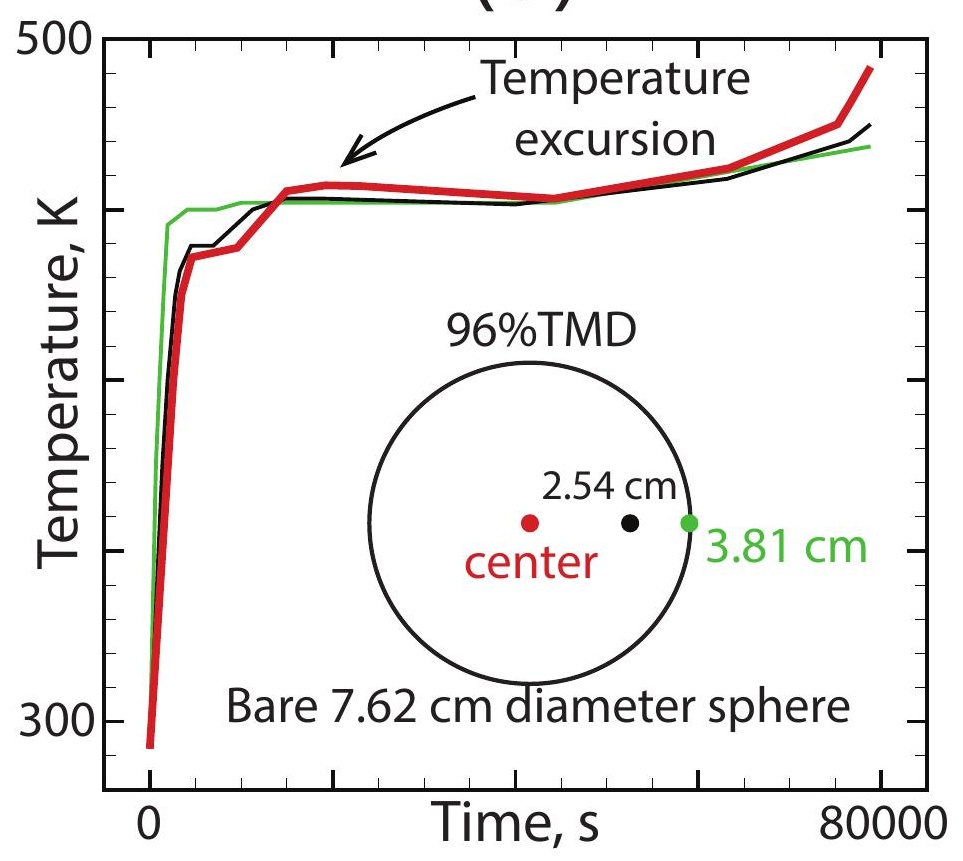


(a) ODTX

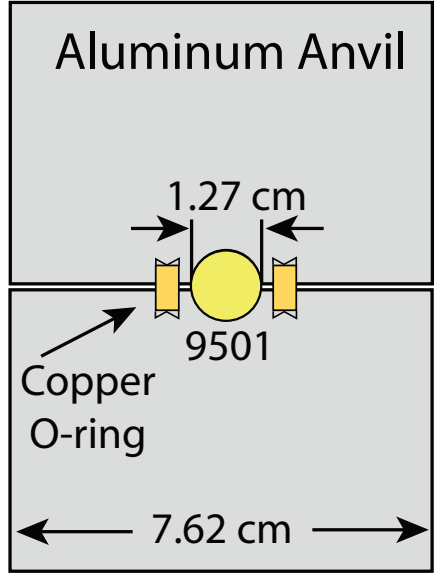

(d) CSAFE-pipe

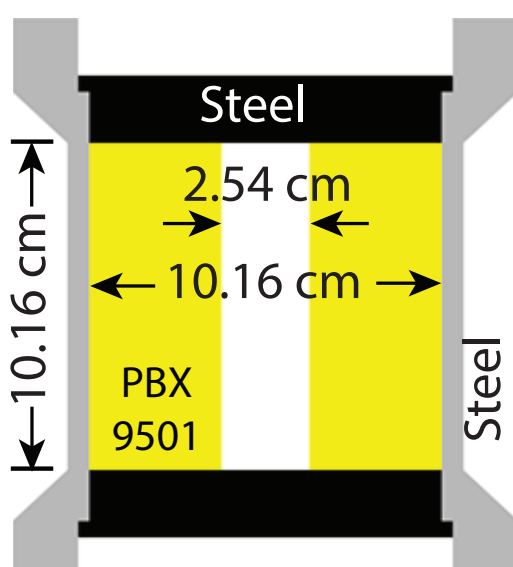

(b) STEX

4130 steel

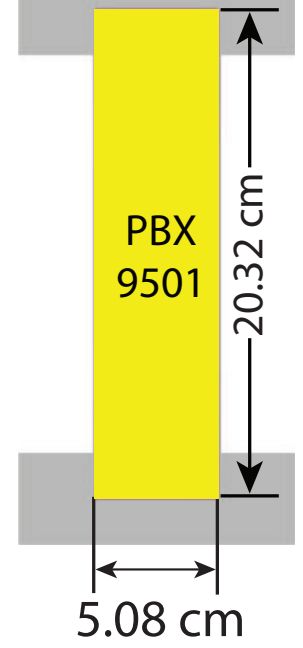

(e) LSAC

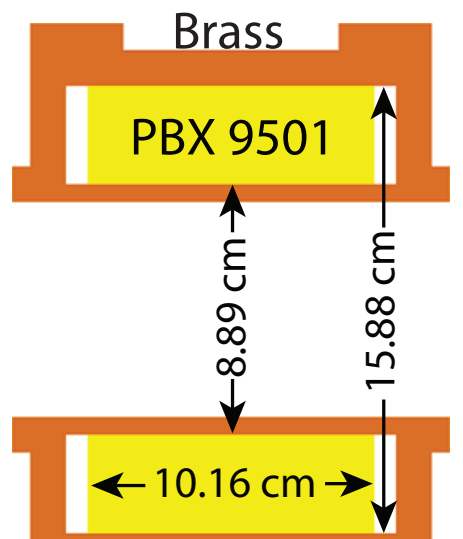

(c) NAWC-pipe

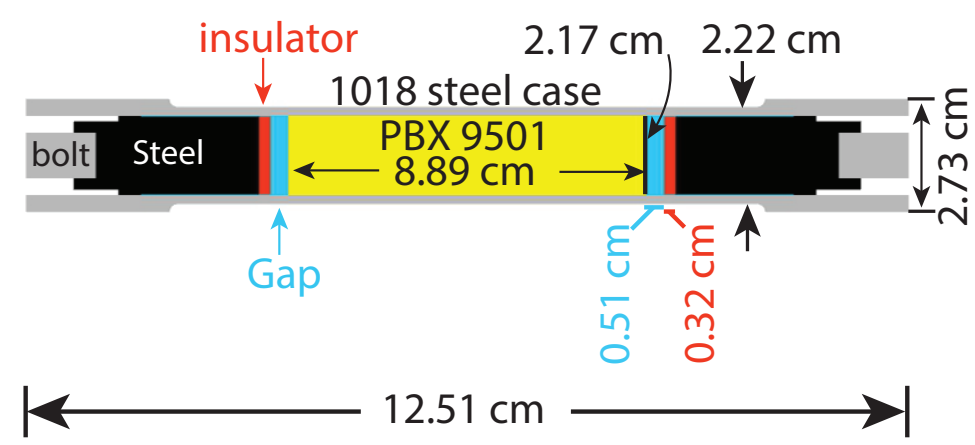

(f) U-sphere

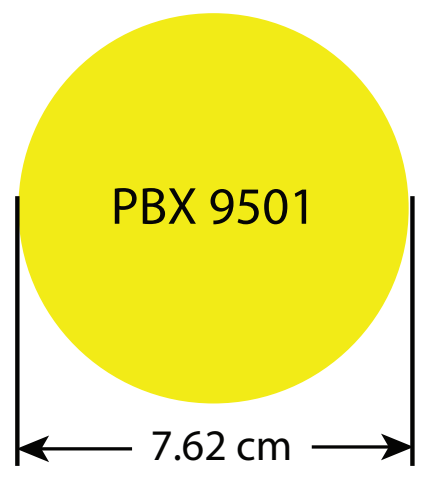




\section{(a) Mechanism}

$\mathrm{H}_{2} \mathrm{O}_{\mathrm{a}} \stackrel{1}{\rightarrow} \mathrm{H}_{2} \mathrm{O}_{\mathrm{g}}$

$\mathrm{BDNPA} / \mathrm{F} \stackrel{2}{\longrightarrow} \mathrm{NVR}+4 \mathrm{NO}_{2}$

Estane $+\mathrm{NO}_{2} \stackrel{3}{\rightarrow} \mathrm{Gas}+\mathrm{C}$

$\mathrm{HMX}+\mathrm{NO}_{2} \stackrel{4}{\longrightarrow} \mathrm{Gas}+\mathrm{C}$

$\mathrm{HMX} \stackrel{5}{\longrightarrow} \mathrm{Gas}+\mathrm{C}$

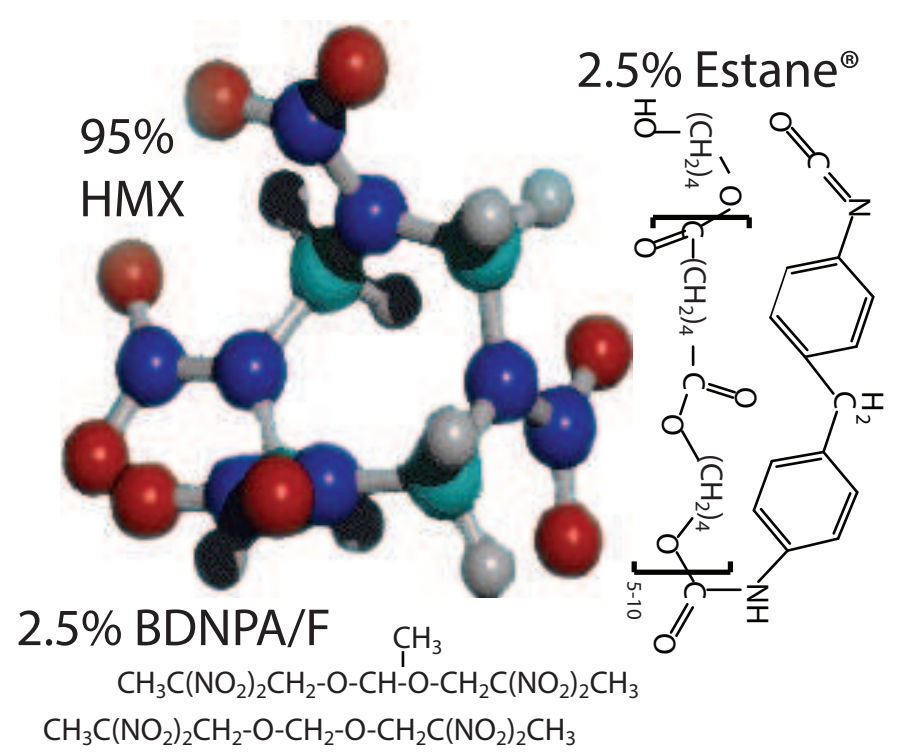

(b) Reaction products and energies

1) Drying $\left(h_{r 1}=2.26 \times 10^{6} \mathrm{~J} / \mathrm{kg}\right.$, endothermic)

2) $\mathrm{NO}_{2}$ evolution $\left(\mathrm{h}_{\mathrm{r} 2}=-2.01 \times 10^{6} \mathrm{~J} / \mathrm{kg}\right.$, exothermic)

BDNPA/F $\left(\mathrm{C}_{7.5} \mathrm{H}_{13} \mathrm{~N}_{4} \mathrm{O}_{10}\right) \rightarrow \mathrm{NVR}\left(\mathrm{C}_{7.5} \mathrm{H}_{13} \mathrm{O}_{3}\right)+4 \mathrm{NO}_{2}$

3) Oxidation of Estane ${ }^{\circledast}\left(\mathrm{h}_{\mathrm{r} 3}=-3.32 \times 10^{6} \mathrm{~J} / \mathrm{kg}\right.$, exothermic)

Estane $\left(\mathrm{C}_{10} \mathrm{H}_{14.6} \mathrm{~N}_{0.4} \mathrm{O}_{3.5}\right)+\mathrm{NO}_{2} \rightarrow 0.7 \mathrm{~N}_{2}+4.5 \mathrm{H}_{2} \mathrm{O}+0.5 \mathrm{CO}_{2}+1.4 \mathrm{CH}_{4}+0.04 \mathrm{H}_{2}+8.1 \mathrm{C}$ Estane $+\mathrm{NO} 2 \rightarrow 7.1 \mathrm{Gas}_{\mathrm{E}}+8.1 \mathrm{C}_{\mathrm{E}}$

4) Oxidation of $\mathbf{H M X}\left(\mathrm{h}_{\mathrm{r} 3}=-7.6 \times 10^{6} \mathrm{~J} / \mathrm{kg}\right.$, exothermic)

$\mathrm{HMX}\left(\mathrm{C}_{4} \mathrm{H}_{8} \mathrm{~N}_{8} \mathrm{O}_{8}\right)+\mathrm{NO}_{2} \rightarrow 4.5 \mathrm{~N}_{2}+4 \mathrm{H}_{2} \mathrm{O}+3 \mathrm{CO}_{2}+\mathrm{C}$

$\mathrm{HMX}+\mathrm{NO}_{2} \rightarrow 11.5 \mathrm{Gas}_{\mathrm{x} 1}+\mathrm{C}_{\mathrm{x} 1}$

5) $H M X$ decomposition into equilibrium products $\left(h_{r 4}=-6.2 \times 10^{6} \mathrm{~J} / \mathrm{kg}\right.$, exothermic) $\mathrm{HMX} \rightarrow 4 \mathrm{~N}_{2}+3.6 \mathrm{H}_{2} \mathrm{O}+2.2 \mathrm{CO}_{2}+0.2 \mathrm{CH}_{4}+1.6 \mathrm{C}$ $\mathrm{HMX} \rightarrow 10 \mathrm{Gas}_{\mathrm{x} 2}+1.6 \mathrm{C}_{\mathrm{x} 2}$ 
Figure 9

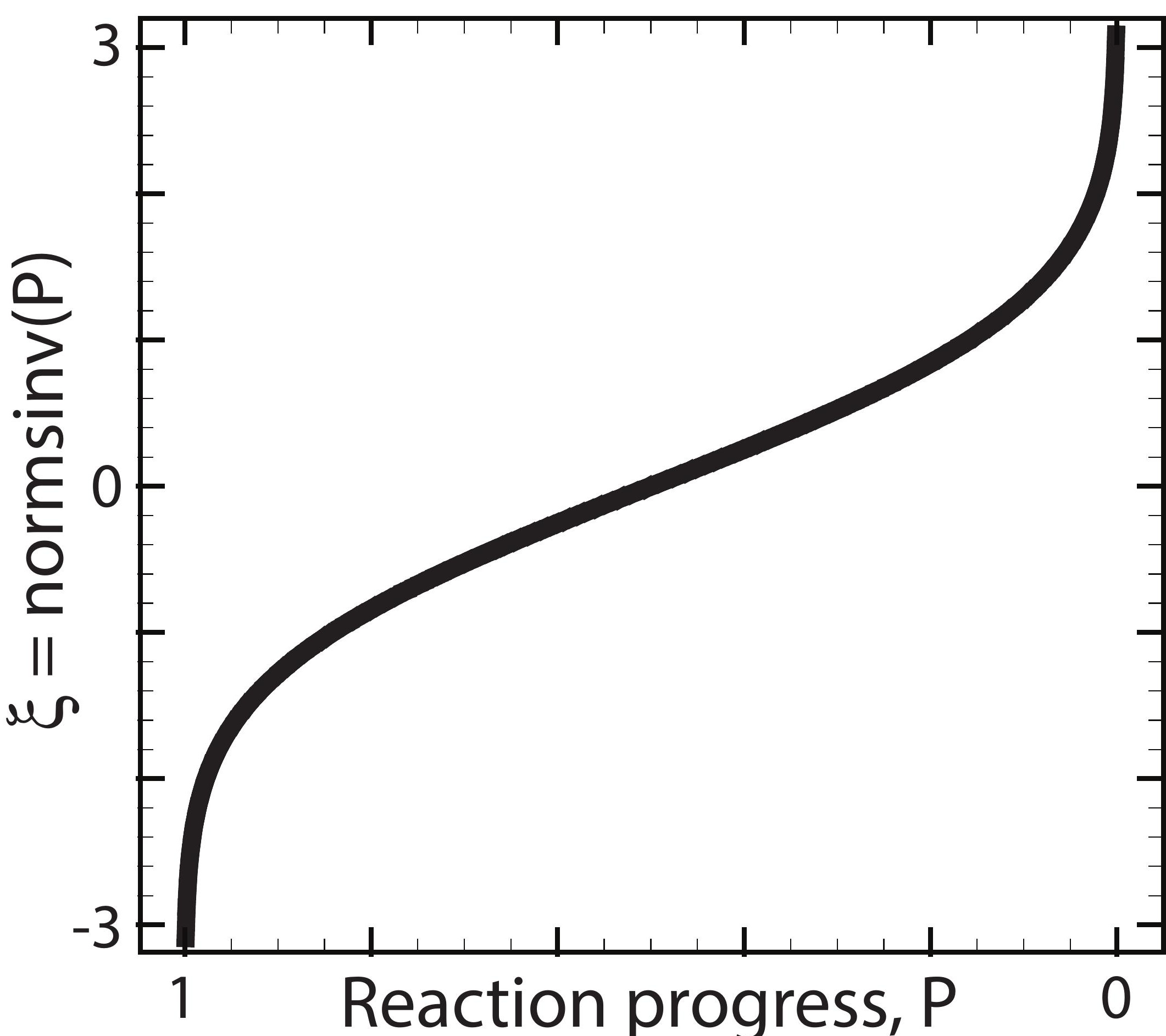


(a)

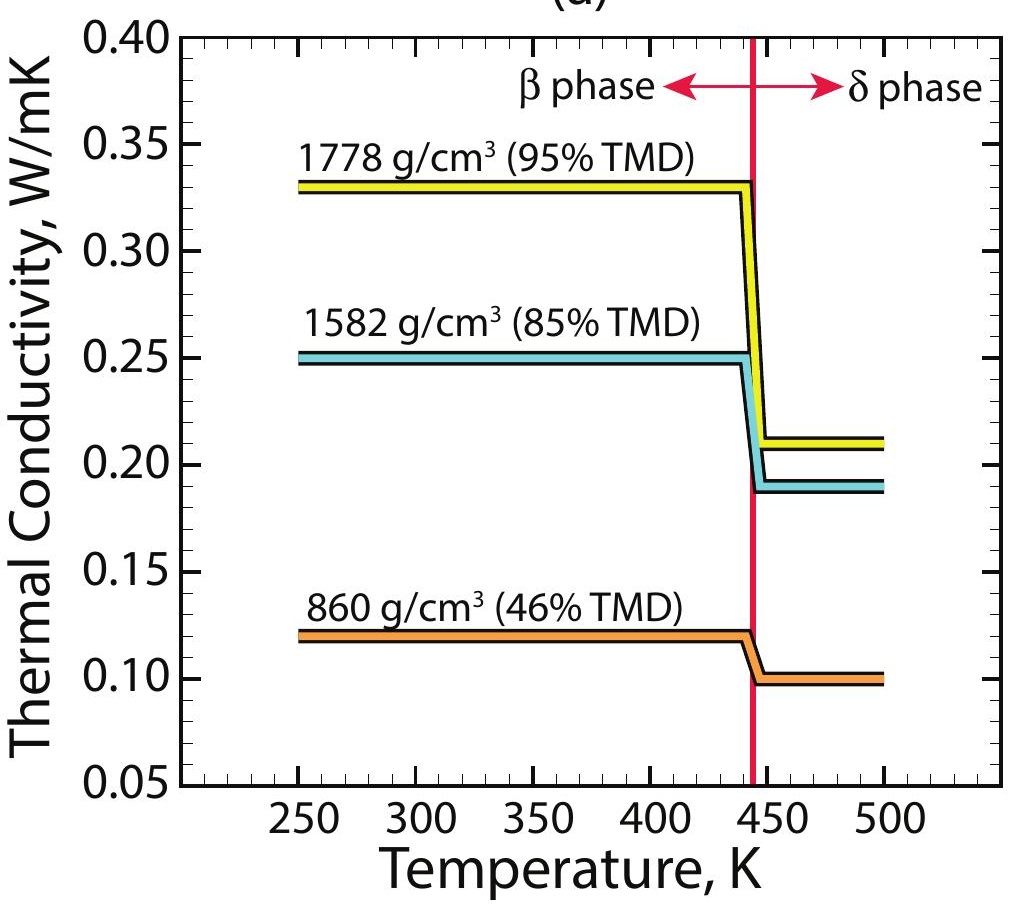

(b)

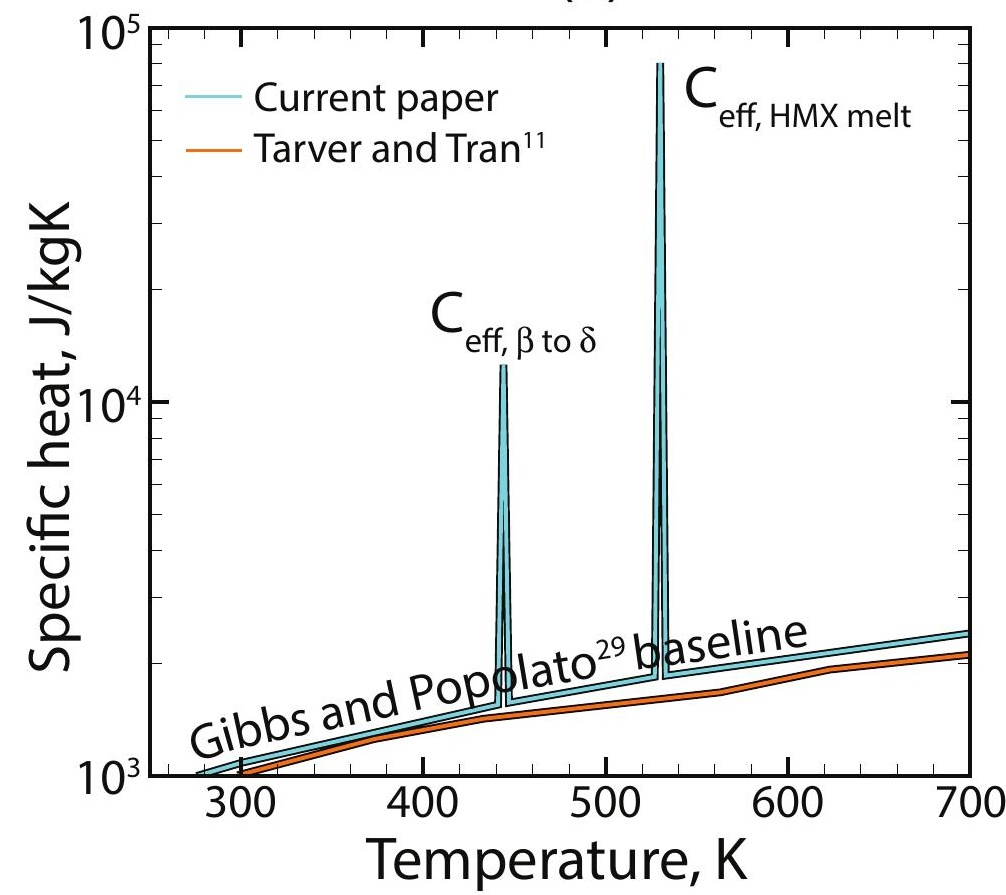




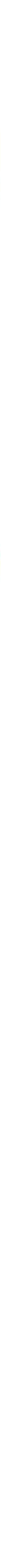

Figure 11 
Legend for (a)-(c):

$\begin{array}{cc}\text { Vented } & \circ \\ \text { Sealed } & \circ\end{array}$

\section{Model with \\ correlation for}

Data binder migration
Model without correlation for binder migration (a)

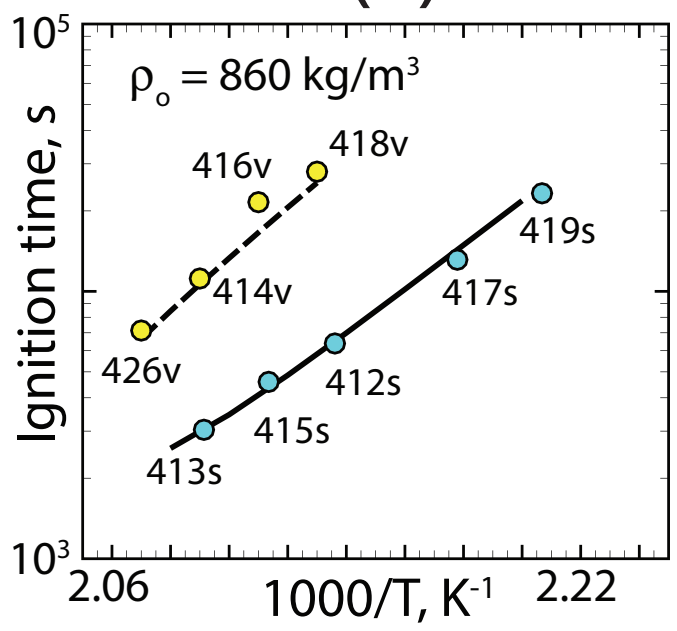

(d)

50

(e)

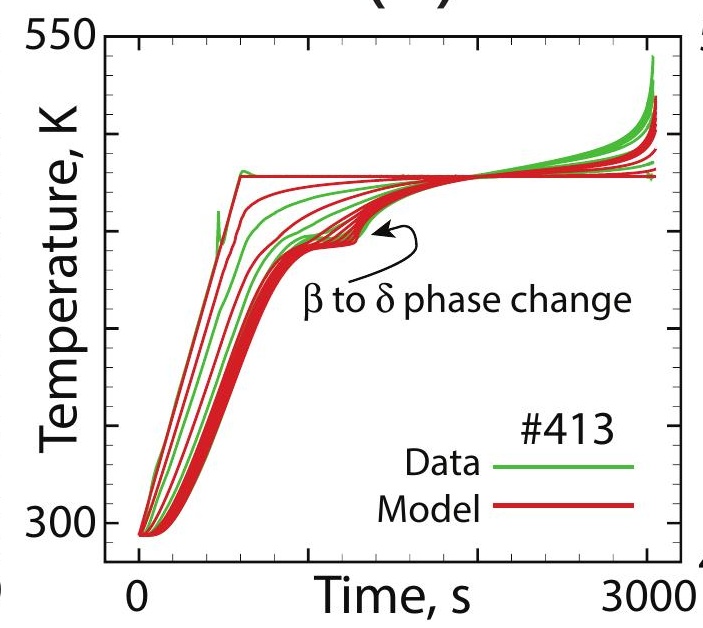

(b)

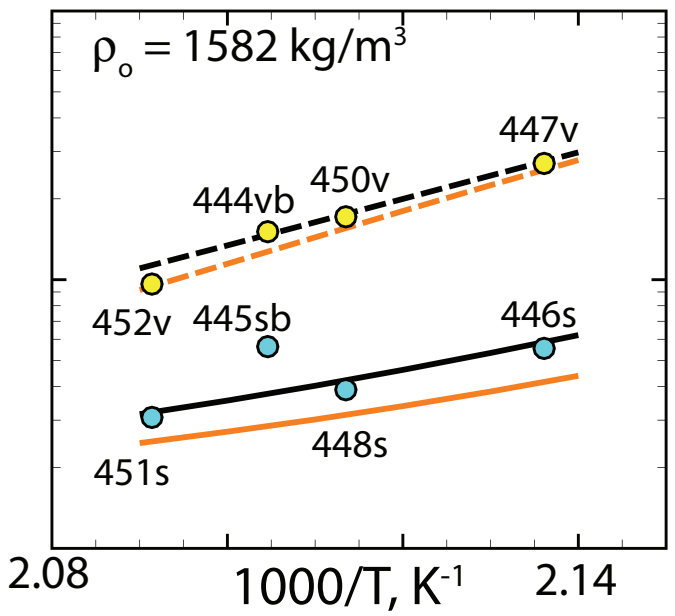

(c)

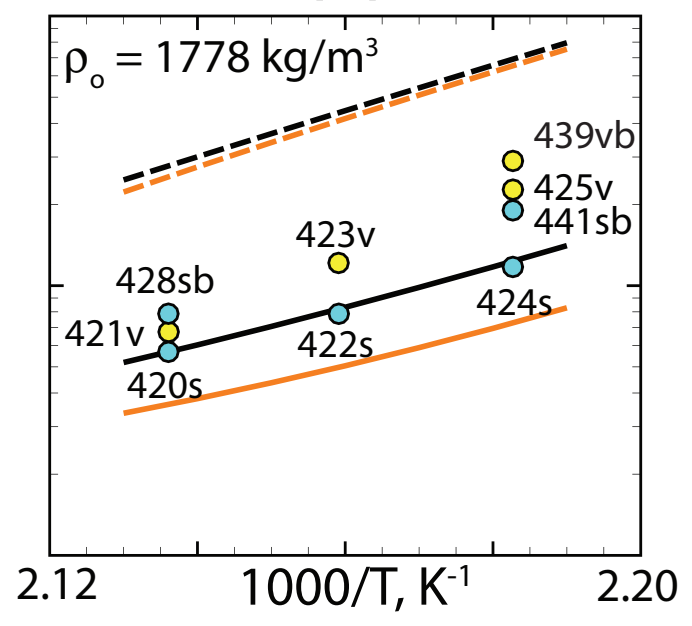

(f)

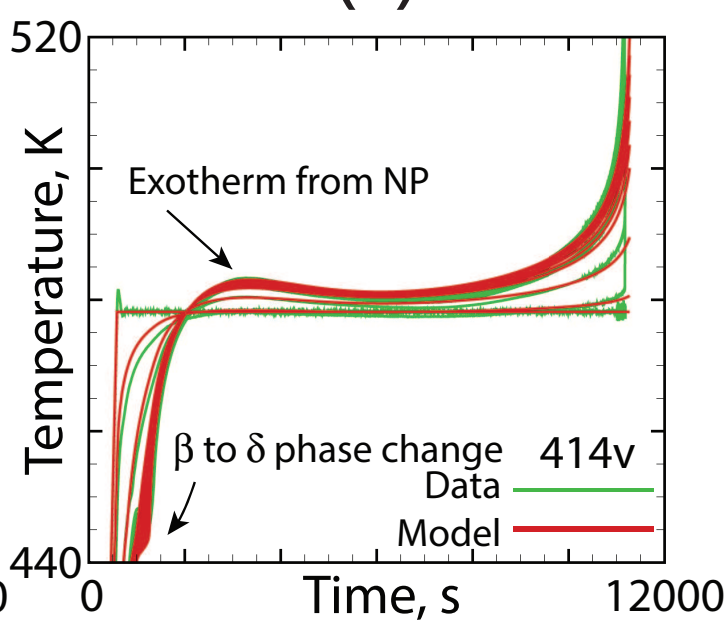


(a)

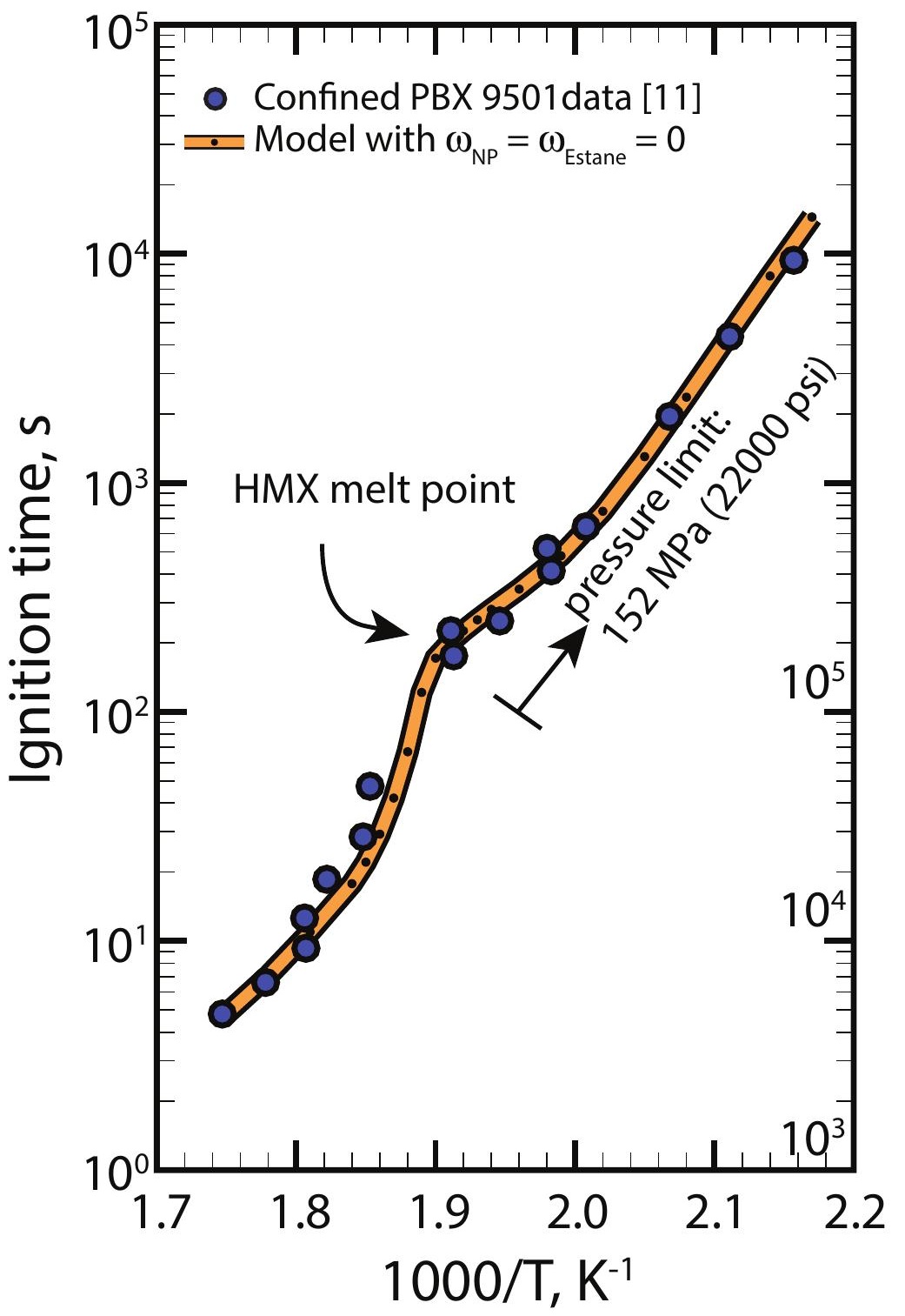

(b)

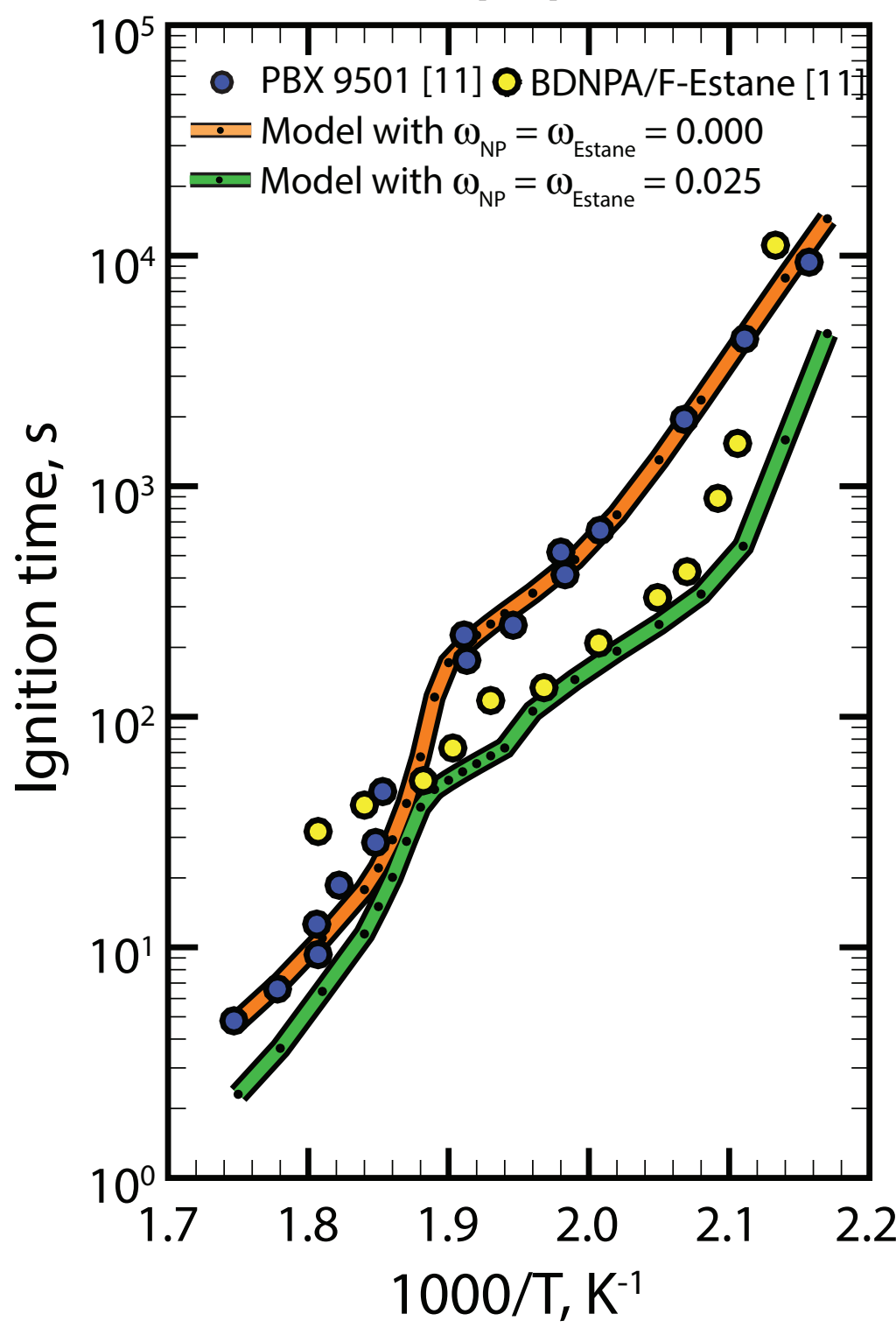


Data [12]

outside of pipe

Model

center to edge in $10 \%$ increments

Pressure limited to $6.9 \mathrm{MPa}$ (1000 psig) based on strain gauge measurements.

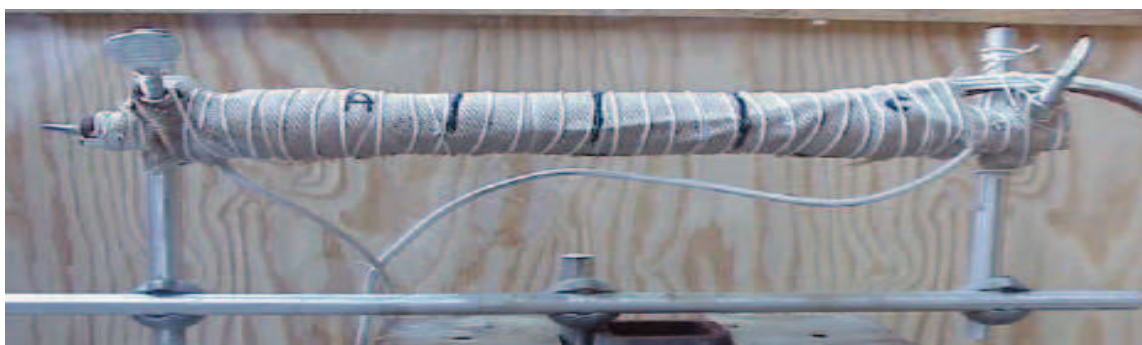

400

350

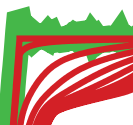

$+$

$\frac{\pi}{2}$
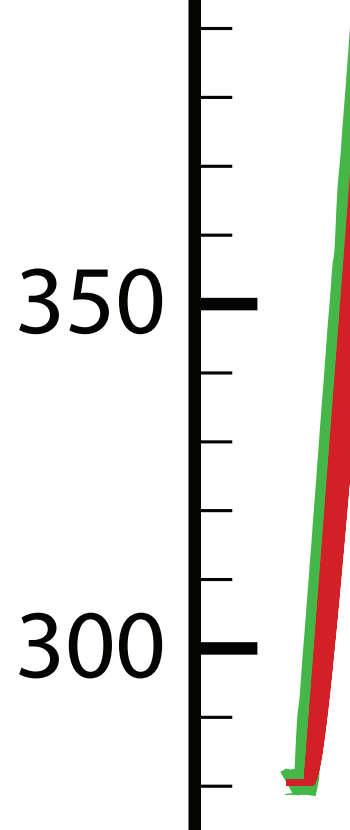

250

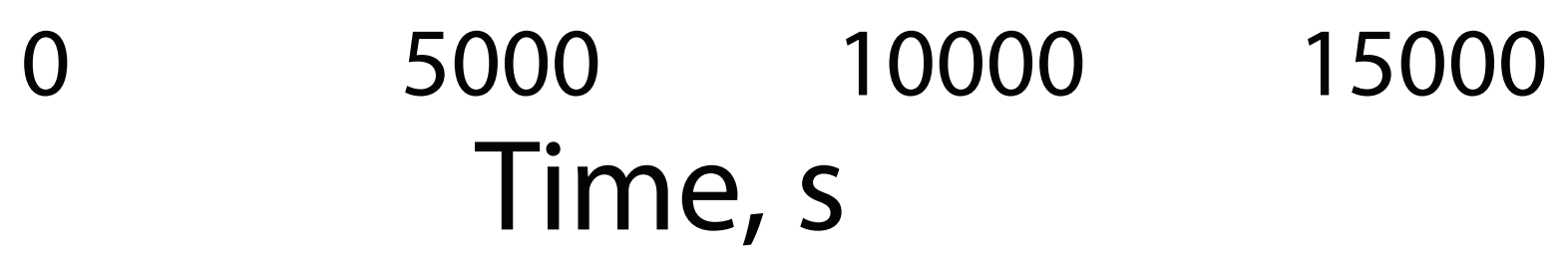


Data [16]

Inside, outside, and $1 / 4,1 / 2$, and $3 / 4$ distance through center of PBX.

Model

Pressure limited to

3.4 MPa (500 psig)

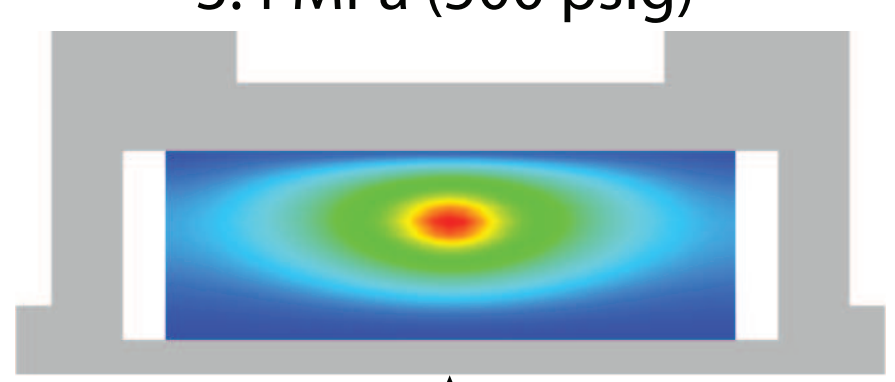

1

$3^{\prime \prime}$

1

300

0

20000

40000

Time, $\mathrm{s}$ 


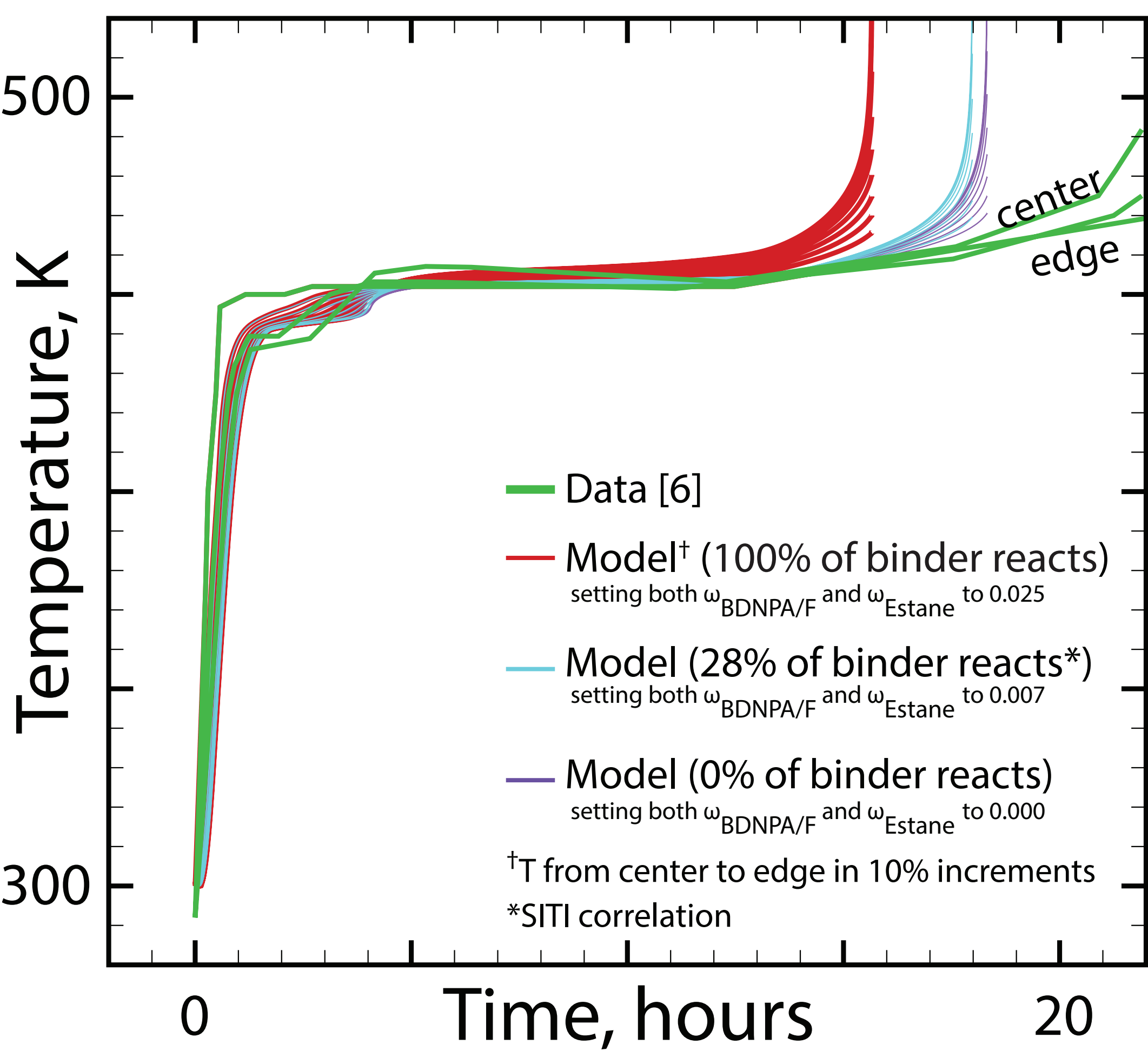


(a)

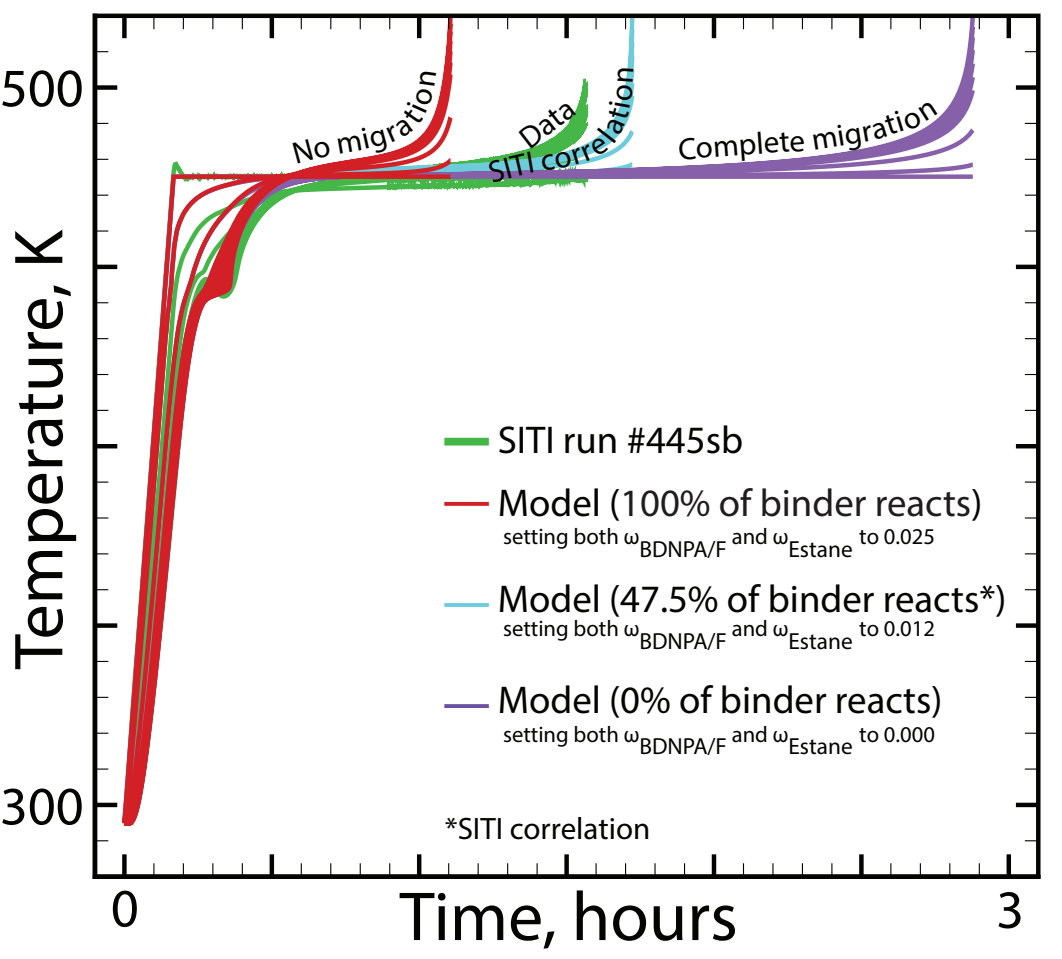

(b)

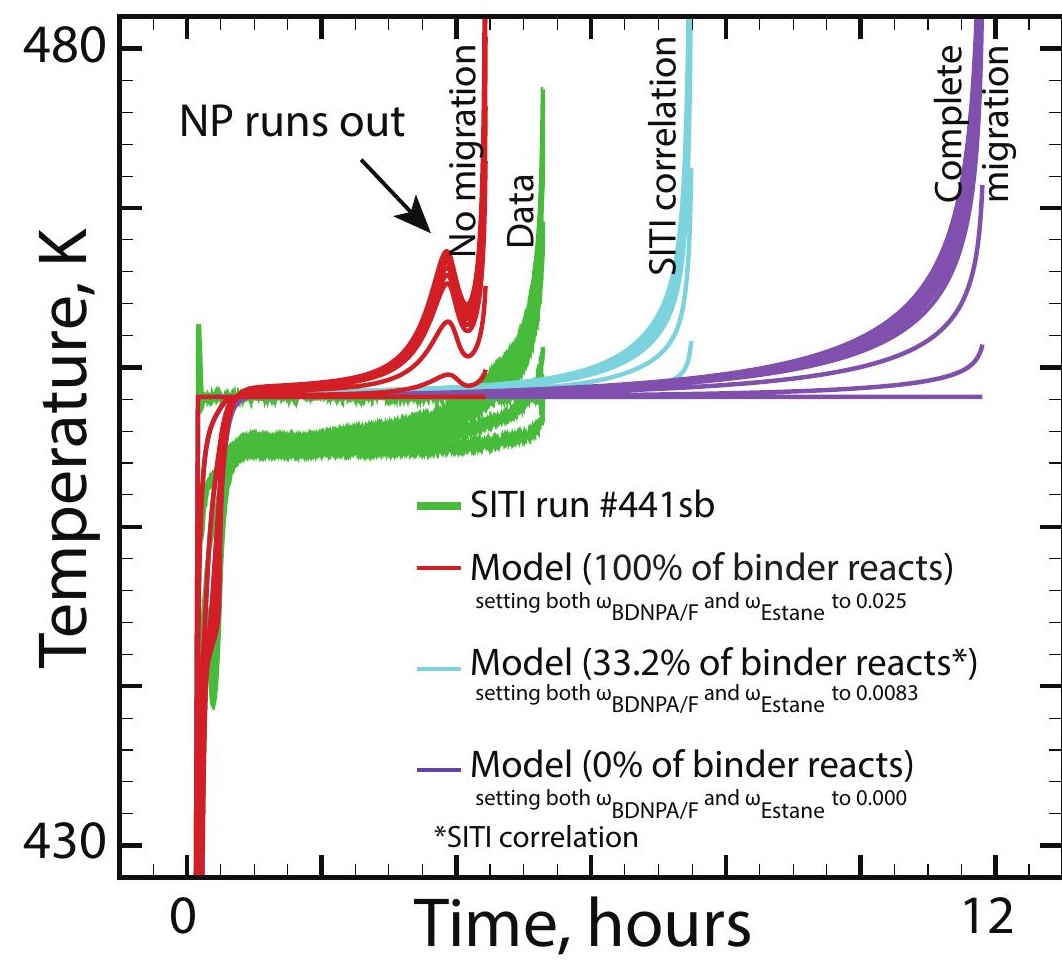


(a)
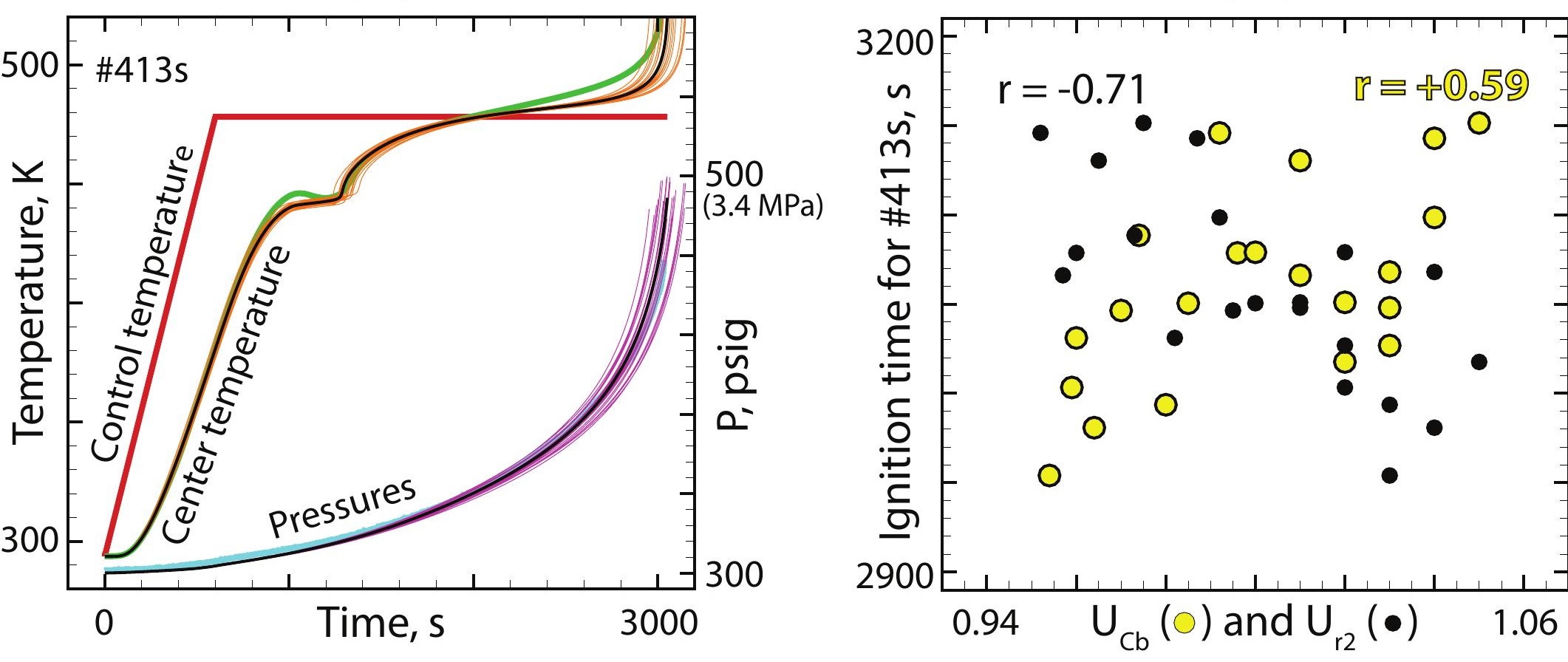

(b) 